\title{
Review Article \\ Hereditary Syndromes Manifesting as Endometrial Carcinoma: How Can Pathological Features Aid Risk Assessment?
}

\author{
Adele Wong ${ }^{1}$ and Joanne Ngeow ${ }^{2,3,4}$ \\ ${ }^{1}$ Department of Pathology and Laboratory Medicine, KK Women's and Children's Hospital, Singapore 229899 \\ ${ }^{2}$ Cancer Genetics Service, National Cancer Centre Singapore, Singapore 169610 \\ ${ }^{3}$ Oncology Academic Clinical Program, Duke-NUS Graduate Medical School, Singapore 169857 \\ ${ }^{4}$ Division of Medical Oncology, National Cancer Centre Singapore, 11 Hospital Drive, Singapore 169610
}

Correspondence should be addressed to Joanne Ngeow; jongeow@gmail.com

Received 4 October 2014; Accepted 23 November 2014

Academic Editor: Ignacio Zapardiel

Copyright (c) 2015 A. Wong and J. Ngeow. This is an open access article distributed under the Creative Commons Attribution License, which permits unrestricted use, distribution, and reproduction in any medium, provided the original work is properly cited.

Endometrial carcinoma is the most common gynecological tumor worldwide. It can be the presenting malignancy, acting as the harbinger, of an undiagnosed hereditary syndrome. Up to $50 \%$ of females with Lynch syndrome present in this manner. Differentiation between Lynch, Muir-Torre, and Cowden syndromes can at times be challenging due to the overlapping features. Our review emphasizes on the strengths, pitfalls, and limitations of microscopic features as well as immunohistochemical and polymerase chain reaction- (PCR-) based tests used by laboratories to screen for DNA mismatch repair (MMR) and PTEN gene mutations in patients to enable a more targeted and cost effective approach in the use of confirmatory gene mutational analysis tests. This is crucial towards initiating timely and appropriate surveillance measures for the patient and affected family members. We also review the evidence postulating on the possible inclusion of uterine serous carcinoma as part of the spectrum of malignancies seen in hereditary breast and ovarian carcinoma syndrome, driven by mutations in BRCA1/2.

\section{Introduction}

Many genetic mutations have been elucidated in the past half century leading to either the discovery or better understanding of hereditary syndromes associated with malignancies in the female genital tract. The discovery of the BRCA1/2 gene in the early 1990s [1] and subsequent work on gene linkage analysis identified it as the main causative gene in hereditary breast and ovarian carcinoma (HBOC) syndrome [2]. Since then, other mutations in molecular pathways such as DNA mismatch repair (MMR) [3] and PTEN [4] have shown to result in syndromes causing endometrial carcinomas, the most common gynecological carcinoma to afflict women worldwide [5].

Gene mutations inherited in a Mendelian fashion have been associated with up to $10 \%$ of all malignancies occurring in humans [6]. As such, it is imperative that syndromes are identified in probands who present with malignancies to enable prompt initiation of appropriate counseling and testing for the individual and family to reduce morbidity and mortality amongst these individuals [7]. As some of these syndromes may have overlapping clinical features, clinicians or geneticists can be faced with a few possible differential diagnoses [8] as summarized in Table 1. In this aspect, close collaboration between oncologists, pathologists, and geneticists is necessary to ensure confirmatory genetic testing proceeds in a cost effective and timely manner for the patient and family members [9].

With the advent of immunohistochemical (IHC) markers and molecular testing for specific gene mutations, anatomic pathologists now play a bigger role than ever aiding oncologists and geneticists towards a more directed approach towards confirmatory genetic testing. This is particularly so for proband patients with sentinel tumors as the initial manifestation for any given family. Although risk assessment and predictive tools for various hereditary syndromes exist 


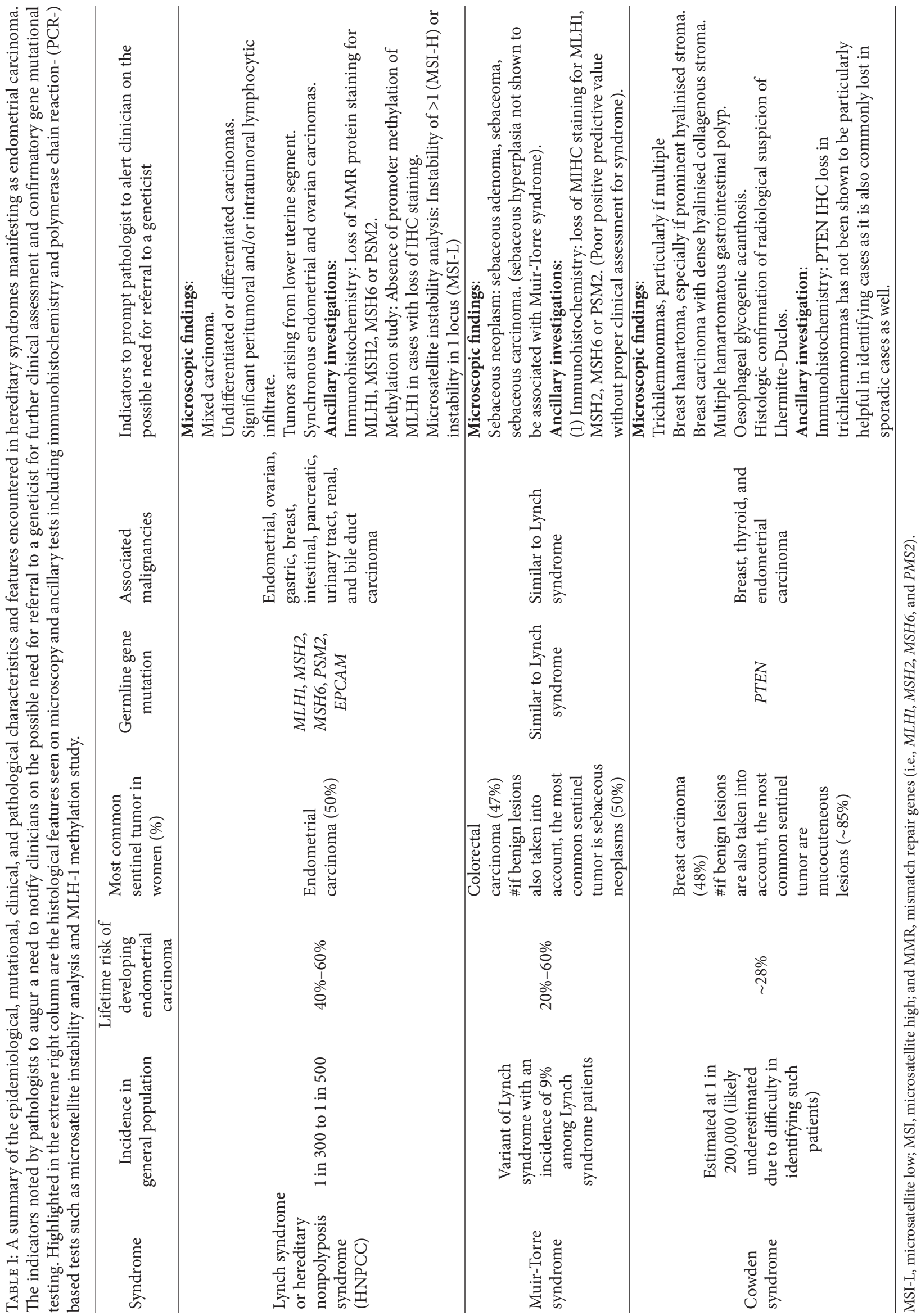


to aid clinician in identifying such patients, some patients fail to fulfill the criteria and are only picked up by pathologists during examination of the tumor tissue specimens.

In this review, we discuss these hereditary endometrial carcinoma syndromes and the important role gynecologists play in identifying at-risk patients as well as in the surveillance of such patients. We further place special emphasis on the role the pathologist plays in terms of appreciating the histological nuances present in tumor tissue using traditional light microscopy as well as the interpretation of newer ancillary investigations performed in the laboratory that may assist clinicians assessing potential patients with an underlying syndrome. We have included HBOC syndrome in this discussion as we wish to highlight the possible association of uterine serous carcinoma with this syndrome. The less common syndromes such as Muir-Torre syndrome and Cowden syndrome are emphasized as these may be missed if clinicians do not actively consider them when assessing patients.

\section{DNA Mismatch Repair (MMR)}

\subsection{Lynch Syndrome}

2.1.1. Background. Lynch syndrome (LS), also known as hereditary nonpolyposis colorectal cancer (HPNCC), is an autosomal dominant syndrome $[10,11]$. The incidence in the general population is estimated to be between 1 in 300 and 1 in 500 [12]. In LS, mutations in the DNA mismatch repair (MMR) gene result in widely dispersed replication errors or instability in highly repetitive error prone areas found primarily in intronic sequences of the genome, known as microsatellites [13]. Microsatellite instability (MSI) can be seen in patients harboring either germline or somatic DNA MMR gene mutations. LS is a result of germline mutations in the DNA MMR genes MLH1, MSH2, MSH6, and PSM2 [14]. Nonhereditary somatic mutation is due to promoter hypermethylation of the $M L H 1$ gene resulting in silencing of the gene causing similar MSI levels in the genome seen in 10\% to $25 \%$ of sporadic tumors, especially colorectal and endometrial carcinomas [15]. Unlike colorectal carcinomas, somatic mutations in the BRAF gene resulting in sporadic cases are far rarer in endometrial carcinomas $[16,17]$. Germline deletions in a non DNA MMR gene, EPCAM, can result in inactivation of $M S H 2$ in approximately $1 \%$ of LS patients [18]. LS patients are at risk of developing colorectal cancer $(80 \%)$, endometrial cancer $(60 \%)$, ovarian cancer $(12 \%)$, and other malignancies in the stomach, pancreas, upper urinary tract, biliary tract, and small intestines [19].

2.1.2. Endometrial Carcinomas in Lynch Syndrome. Approximately $2 \%$ to $6 \%$ of all endometrial carcinomas can be attributed to germline mutations in the DNA MMR genes $[20,21]$. Up to $50 \%$ of female patients with LS will present with endometrial carcinoma as their sentinel tumor [19, 22]. Germline mutation in the MSH6 gene is associated with the highest risk for developing endometrial carcinomas [23, 24]. Mutations in $\mathrm{MLH1}$ and MSH6 genes result in a higher risk of developing colorectal carcinoma [25]. Individuals with germline mutations in PMS2 have the lowest overall risk of developing LS-associated tumors [26]. The median time for LS patients with endometrial carcinoma to develop a second tumor is estimated to be 11 years [27]. Therefore, identification of proband LS patients with endometrial carcinomas can result in timely and appropriate management to help reduce the potential of a second tumor in the patient or, in the case of her relatives, preventing tumors all together.

\subsubsection{Identification of Lynch Syndrome amongst Proband Patients with Endometrial Carcinoma}

(1) Clinical Evaluation. LS patients have traditionally been identified by clinical assessment using validated criteria followed by confirmatory gene testing as described in Table 2. Sensitivity and specificity were increased in the 2004 revised Bethesda guidelines but still fell short due to the failure to specify gynecological tumors requiring further testing [28]. Among women with LS presenting with endometrial carcinomas, between $50 \%$ and $70 \%$ do not meet the Amsterdam or Bethesda guidelines due to the absence of a personal or family history suggestive of LS [20, 29-31]. Mutations in MSH6 and PSM2 are more likely to result in failure to meet either of the guidelines [29]. Clinical predictive tools relying on personal and family history such as $\operatorname{PREMM}_{1,2,6}$, MMRpredict, and MMRpro have been developed to quantify the risk of harboring germline DNA MMR mutations in colorectal patients [32]. Risk is determined by calculating the area under the receiver curve (AUC) with a $\geq 5 \%$ cutoff [33]. A large study involving 563 patients with endometrial carcinomas showed the three predictive tools to be having inferior sensitivity and specificity compared with IHC and polymerase chain reaction- (PCR-) based MSI analysis in identifying patients requiring confirmatory germline DNA MMR gene testing [33].

The deficiencies of the Amsterdam and Bethesda guidelines have resulted in the implementation of utilization of IHC and/or MSI analysis on tumor tissue to boost the ability to identify patients with LS. The Evaluation of Genomic Applications in Practice and Prevention (EGAPP) working group recommends IHC and MSA testing to be offered to all newly diagnosed colorectal carcinoma patients as part of the workup to identify all possible LS individuals [34, 35]. Currently, this proposal does not extend to include endometrial carcinoma patients. The Society of Gynecologic Oncologists (SGO) and National Comprehensive Cancer Network (NCCN) have only proposed blanket IHC and/or MSI analysis of women with endometrial carcinoma under the age of 50 years [36]. However, the suggestion to offer universal testing has been advocated as many proband LS patients present with endometrial carcinoma as their sentinel tumor without appropriate family history to trigger IHC and/or MSI analysis testing. Furthermore, the majority of LS patients will present with endometrial carcinoma at 50 years and above $[20,21,37]$. The SGO and NCCN guidelines very likely fail to optimally identify patients with LS and subsequent initiation of appropriate cancer surveillance.

(2) Histological Evaluation. Endometrial carcinomas associated with LS have been shown to exhibit a tendency to occur 
TABLE 2: Amsterdam I and II criteria as well as the Revised Bethesda Guidelines for diagnosis of Lynch syndrome. The Revised Bethesda Guidelines was developed with the intention of identifying individuals who should undergo investigation for Lynch syndrome by evaluation of MSI analysis and/or immunohistochemistry (IHC) testing of their tumors. (Adapted from [43]).

\section{Amsterdam I criteria}

(i) Three or more relatives with histologically verified colorectal cancer, one of which is a first-degree relative of the other two. Familial adenomatous polyposis should be excluded.

(ii) Two or more generations with colorectal cancer.

(iii) One or more colorectal cancer cases diagnosed before the age of 50 years.

\section{Amsterdam II criteria}

(i) Three or more relatives with histologically verified Lynch syndrome-associated cancer (colorectal cancer, cancer of the endometrium, small bowel, ureter, or renal pelvis), one of which is a first-degree relative of the other two. Familial adenomatous polyposis should be excluded.

(ii) Cancer involving at least two generations.

(iii) One or more cancer cases diagnosed before the age of 50 years.

\section{Revised Bethesda Guidelines}

(i) Colorectal carcinoma diagnosed at younger than 50 years.

(ii) Presence of synchronous or metachronous colorectal carcinoma or other Lynch Syndrome-associated tumors ${ }^{\#}$.

(iii) Colorectal carcinoma with MSI-high pathologic-associated features (Crohn-like lymphocytic reaction, mucinous/signet cell differentiation, or medullary growth pattern) diagnosed in an individual younger than 60 years old.

(iv) Patient with colorectal carcinoma and colorectal carcinoma or Lynch syndrome-associated tumor diagnosed in at least 1 first-degree relative younger than 50 years old.

(v) Patient with colorectal carcinoma and colorectal carcinoma or Lynch syndrome-associated tumor ${ }^{\#}$ at any age in two first-degree or second-degree relatives.

\# Lynch syndrome-associated tumors include tumor of the colorectum, endometrium, stomach, ovary, pancreas, ureter, renal pelvis, biliary tract, brain, and small bowel.

Caveat: Muir Torre syndrome is considered a subset of Lynch syndrome with patients also having sebaceous neoplasms and/or keratoacanthomas.

in the lower uterine segment (LUS) with up to third of such tumors attributed to this syndrome [38]. Histologically, LSassociated tumors have a diverse morphological appearance. The most common subtype is endometrioid carcinoma but serous carcinoma, clear cell carcinoma, and carcinosarcoma are also well accounted for [39]. Nonendometrioid carcinomas such as clear cell carcinoma, serous cell carcinoma, and carcinosarcoma are known to occur in LS patients at a younger age than is commonly seen in non-LS patients [40]. There is also a well-documented predisposition for LS-associated tumors to exhibit high grade features with a mixed histology which can at times represent a huge challenge to anatomic pathologists attempting to subtype the tumor components into the various neat categorical variants [41, 42]. Difficulty in separating the various tumor components comprising endometrioid, serous, and/or clear cell carcinomas is not uncommon in such situations [42]. Interestingly, tumors seen arising in the LUS have been shown to occasionally disclose histological and immunohistochemical features which are difficult to ascertain if the tumor is an endometrial or endocervical primary adenocarcinoma [38].

Among tumors with an endometrioid appearance, a few histological features have been shown to suggest the possibility of an underlying MSI. Undifferentiated and dedifferentiated endometrioid carcinomas have been associated with MSI, in particular MLH1/PMS2 gene mutation, due to either promoter methylation or germline mutation [40, $46,47]$. Undifferentiated endometrioid carcinomas consist of solid sheets of round to polygonal cells with vesicular nuclei and prominent nucleoli without any evidence of gland formation [48]. A tumor is deemed to be dedifferentiated when areas of moderately or even well differentiated endometrioid carcinoma are discernible [48]. Another histological feature often associated with MSI, both in germline mutated or sporadic promoter methylated tumors, is a heavy lymphocytic infiltrate within and around the endometrial carcinomas [46, 49].

Synchronous ovarian and endometrial tumors have also been connected to MSI. The most common pattern is that of endometrioid carcinomas in both the endometrium and ovary [50-52]. However, some patients may exhibit synchronous clear cell or undifferentiated carcinomas [50]. Serous carcinomas are uncommon. Gynecologists practicing in centers conducting universal screening for LS using IHC should consider requesting for the test to be performed when encountering young patients with ovarian cell carcinomas. This is due to a strong association with LS in patients in this age group [50]. This should also be extended to patients with synchronous uterine endometrioid carcinoma and ovarian clear cell carcinoma as rare reports have been documented in MSI patients $[47,50]$.

(3) Ancillary Laboratory Tests. The current gold standard confirmatory test for LS is the expensive gene mutational analysis of DNA MMR genes [21]. Cost effective and readily available screening tools available in most laboratories are (1) IHC to look for abnormal loss of DNA MMR proteins, (2) MSI analysis by PCR to detect for increased microsatellite 
TABLE 3: Endometrial carcinoma testing result using MSI analysis and/or immunohistochemistry with additional testing strategies for Lynch Syndrome. Additional suggested testing strategies for patients who have been tested using either MSI analysis and/or immunohistochemistry with a four-panel marker (MHL1, MSH2, MSH6, and PMS2) or a "two-panel marker (MSH6 and PMS2) (adapted from [43]).

\begin{tabular}{|c|c|c|c|c|c|c|}
\hline \multirow[t]{2}{*}{ MSI analysis } & \multicolumn{4}{|c|}{$\begin{array}{l}\text { Immunohistochemistry protein } \\
\text { expression }\end{array}$} & \multirow[t]{2}{*}{ Possible causes } & \multirow[t]{2}{*}{ Further action } \\
\hline & MLH1 & $\mathrm{MSH} 2$ & MSH6 $^{\#}$ & $\mathrm{PMS}^{\#}$ & & \\
\hline MSS/MSI-L & + & + & + & + & Sporadic carcinoma & None. \\
\hline MSI-H & + & + & + & + & $\begin{array}{l}\text { Germline mutation in } \\
\text { MMR or EPCAM genes }\end{array}$ & $\begin{array}{l}\text { MLH1, MSH2, then MSH6, } \\
\text { PMS2, and EPCAM genetic } \\
\text { testing }\end{array}$ \\
\hline MSI-H & NA & NA & NA & NA & $\begin{array}{l}\text { Sporadic or germline } \\
\text { mutation in the MMR or } \\
\text { EPCAM genes }\end{array}$ & $\begin{array}{l}\text { Consider IHC to guide } \\
\text { germline testing if IHC is } \\
\text { not done germline testing } \\
\text { of MLH1, MSH2, MSH6, } \\
\text { PMS2, and EPCAM genes }\end{array}$ \\
\hline MSI-H or NA & - & + & + & - & $\begin{array}{l}\text { Sporadic cancer or } \\
\text { germline mutation of } \\
\text { MLH1 }\end{array}$ & $\begin{array}{l}\text { MLH1 promoter } \\
\text { methylation testing. MLH1 } \\
\text { genetic testing if absent } \\
\text { hypermethylation or if } \\
\text { testing not done }\end{array}$ \\
\hline MSI-H or NA & - & + & + & + & Germline mutation MLH1 & MLH1 genetic testing \\
\hline MSI-H or NA & + & + & + & - & $\begin{array}{l}\text { Germline mutation of } \\
\text { PMS2, rarely MLH1 }\end{array}$ & $\begin{array}{l}\text { PMS2 genetic testing if } \\
\text { negative MLH1 testing }\end{array}$ \\
\hline MSI-H or NA & + & - & - & + & $\begin{array}{l}\text { Germline mutation of } \\
\text { MSH2 or EPCAM, rarely of } \\
\text { MSH6 }\end{array}$ & $\begin{array}{l}\text { MSH2 genetic testing, if } \\
\text { negative EPCAM, if } \\
\text { negative MSH6 }\end{array}$ \\
\hline MSI-H or NA & + & - & + & + & $\begin{array}{l}\text { Germline mutation of } \\
\text { MSH2 }\end{array}$ & $\begin{array}{l}\text { MSH2 genetic testing if } \\
\text { negative EPCAM testing }\end{array}$ \\
\hline MSI-H, MSI-L or MSS & + & + & - & + & $\begin{array}{l}\text { Germline mutation of } \\
\text { MSH6, less likely MSH2 }\end{array}$ & $\begin{array}{l}\text { MSH2 genetic testing if } \\
\text { negative MSH6 testing }\end{array}$ \\
\hline
\end{tabular}

MSI-L, microsatellite low; MSI, microsatellite high; MMR, mismatch repair genes (i.e., MLH1, MSH2, MSH6, and PMS2); NA, not available; +, protein expression present in tissue; and -, protein expression not present in tissue.

repeats in specific loci and when required, and (3) MLH1 promoter methylation also utilizing PCR [21]. The usual initial workflow to identify DNA MMR genes is by IHC for the 4 DNA MMR proteins ( $M L H 1, P M S 2, M S H 2$, and MSH6) and/or MSI analysis [53]. Some centers perform both tests on every tumor specimen to maximize detection $[20,22,54]$ as described in Table 3. Tumor testing by IHC and/or MSI analysis has been reported to generally detect abnormal DNA MMR protein expression in $15-25 \%$ of unselected patients with endometrial carcinomas $[20,33]$. Subsequent to this, all MSI patients exhibiting loss of DNA MMR protein $M L H 1$ expression can be further segregated using $M L H 1$ gene methylation testing to identify those with as somatic promoter methylation and those most likely to benefit from confirmatory germline mutational analysis $[53,54]$. In contrast to patients with colorectal cancers [16], patients with sporadic MSI MLH1 methylated endometrial carcinomas do not benefit from additional testing for V600E mutation of the $B R A F$ gene as less than $1 \%$ display this mutation $[17,55]$.

(a) Immunohistochemistry (IHC). IHC is performed on paraffin embedded tumor tissue. The sensitivity and specificity when using the four DNA MMR protein markers are $91 \%$ and $83 \%$, respectively [56]. However, it is important to recognize that IHC will not detect germline mutations where the DNA MMR protein is produced but nonfunctioning as in the case of missense mutations [57].

Normal DNA MMR proteins function as heterodimer complexes by forming pairs of dimers with $M L H 1$ partnering PMS2 and MHS2 pairing up with MSH6, with MLH1 and $\mathrm{MSH} 2$ acting as obligatory partners [58, 59]. Mutation in one of the protein in the pairing results in concurrent loss of staining of its partner protein. Somatic mutation via epigenetic methylation silencing of the $M L H 1$ promoter gene results in loss of PMS2 IHC staining. Epigenetic silencing can also occur in the $\mathrm{MSH} 2$ gene following deletions in the EPCAM gene leading to loss of IHC staining in the partner protein, MSH6 [18]. Germline mutations in MSH6 or PMS2 genes do not result in loss of IHC staining in its obligatory partner [57, 60]. Individual loss of PMS2 or MSH6 IHC staining indicates the possible germline mutations in the respective genes $[57,60]$. As such, a two IHC panel utilizing PMS2 and MSH6 is feasible [61].

An abnormal IHC staining pattern is where there is a total loss of nuclear staining in tumor cells [10]. Normal staining is seen in lymphocytes, stroma, and normal endometrium and these act as internal positive controls. A common problem arising from normal staining of intratumoral lymphocytes 
is mistaking these for tumor cells, resulting in false positive result of normal retention of MSI in the tumor [62-64]. Another common challenge is the difficulty in assessing the heterogeneous staining nature of the MSH6 IHC marker [63]. Only small areas may exhibit normal retention of nuclear staining. As such, tumor tissue of an adequate size should be selected for IHC staining. When accurate interpretation on a tissue block remains problematic despite repeated testing, an equivocal or inconclusive report will be rendered with the recommendation to consider an alternative test such as MSI analysis.

(b) Polymerase Chain Reaction (PCR). MSI analysis is a PCR test which measures errors in DNA replication caused by loss or abnormal function of the DNA MMR protein. It is performed on paraffin-embedded tumor tissue using either mononucleotides only or a combination of nucleotides and dinucleotides to amplify common sites of instability in the genome $[35,65,66]$. The Bethesda MSI panel consists of two mononucleotides and three dinucleotides (BAT25, BAT26, D2S123, D5S346, and D17S250) [67] and is still widely used despite two well-known pitfalls caused by the dinucleotides [66]. The National Cancer Institute (NCI) panel of five mononucleotide markers (BAT25, BAT26, NR21, NR24, and NR27) in contrast has been shown to be more effective and reproducible $[62,66,68]$. MS-stable (MSS) phenotype tumors will show normal microsatellite repeats as normal tissues [65]. MSI-high (MSI-H) tumors show microsatellite instability in two or more of the tested loci while MSI-low (MSI-L) tumors show instability at one locus [65]. Although MSI-H is seen when germline mutation occurs in any of the four DNA MMR genes, mutations in MSH6 more frequently results in MSI-L or even MSS status [14, 20, 69, 70]. MSS MSH6 mutated cases are more commonly seen with the use of the Bethesda panel $[69,70]$. One study previously showed $11.8 \%(12 / 102)$ of MSI-H tumors retained normal IHC staining, of which $2 / 12$ of the discordant cases were patients with endometrial carcinomas and a family history of LS [54]. Possible reduced detection rates can occur in centers only relying on IHC. As such, MSI analysis is concurrently used in conjunction with IHC for testing in some centers [54]. MSI analysis is not capable of differentiation between tumors with $M L H 1$ promoter methylation and germline mutation [65]. Tumors with loss of MLH1 IHC staining will need to undergo an additional PCR-based test to detect for $M L H 1$ gene promoter methylation $[15,71]$. A patient with a tumor which tests negative with the $M L H 1$ gene promoter methylation test should be encouraged to undergo germline mutation testing for LS [71].

(c) Confirmatory Gene Mutational Analysis for Lynch Syndrome. Direct gene sequencing using the traditional Sanger sequencing method to uncover mutations in DNA MMR genes is carried out in conjunction with multiplex ligationdependent probe amplification (MLPA) [20, 21]. MLPA is utilized to detect large genomic rearrangements. MLPA is also used to detect deletions in the EPCAM gene, which results in somatic methylation of the $\mathrm{MSH} 2$ gene [72].
Some gene mutational analysis results of the four DNA MMR genes will indicate missense mutations [73], the significance of which is often unknown and are classified under the "variants of uncertain significance" (VUS) category [74]. A certain proportion of patients with IHC and/or MSI analysis results suggestive of LS will have no mutations in DNA $M M R$ genes [73]. Current sequencing protocols may not be sufficiently sensitive to identify such mutations which reside deep within the introns or promoter regions of the genes. Unknown novel epigenetic effects have also been postulated as a cause.

2.1.4. Recommended Surveillance. One of the main aims of identifying proband patients with LS is to unearth unsuspecting relatives who are carriers of the deleterious DNA MMR genes. The general expert consensus is that surveillance for the patient and family members with LS is required [54, 75] as highlighted in Table 4 .

We concentrate on endometrial surveillance required for the proband's female family members. Female relatives of LS proband patients who are suspected or confirmed to be DNA MMR mutation carriers should be offered the option to undergo surveillance in the effort to prevent endometrial carcinomas. There is some support for the use of transvaginal ultrasound and endometrial biopsy either annually or every 2 years from the age of 30 to 35 [76]. In a recent retrospective study over a 10-year period, gynecologists were the designated physicians to perform surveillance colonoscopy and endometrial curettage under sedation to reduce discomfort, at the same outpatient visit scheduled every 1 to 2 years apart [77]. Endometrial curettage usually provides a large amount of tissue compared to other biopsy methods and is, thus, an added advantage during histological examination. The 55 LS mutation carriers in this study had a combined 111 surveillance visits with 4.5\% (5/111) of these visits resulting in abnormal biopsy findings. Four patients had complex hyperplasia and one patient was diagnosed with endometrioid carcinoma, FIGO grade 1 stage la. The patient with endometrioid carcinoma and three others with complex hyperplasia did not have thickened endometrium on transvaginal ultrasound to warrant a biopsy. With the findings by Nebgen et al. [77] in mind, it is prudent that if it is decided that no active surveillance is to be carried out, female carriers of the DNA MMR gene mutations must be educated on the need to seek immediate medical attention for further investigation if they have any abnormal uterine bleeding.

\subsection{Muir-Torre Syndrome, a Variant of Lynch Syndrome}

2.2.1. Background. Muir-Torre syndrome (MTS) is now considered a subtype of LS $[78,79]$ with an estimated overall frequency of $9.2 \%$ among individuals with LS [80]. MTS is mostly due to germline mutations in MSH2 and MLH1 [81]. It is characterized by sebaceous gland neoplasms (except sebaceous hyperplasia) and keratoacanthoma with 57\% of patients presenting with diagnostic skin lesions as their sentinel pathology $[81,82]$. Recognition of MTS is a problem and may stem from patients considering these lesions as insignificant and not disclosing in their medical histories 
TABLE 4: Guidelines for screening at-risk or affected persons with Lynch syndrome. Recommendations are based on the strength of confidence and Grades of Recommendation, Assessment, Development, and Evaluation (GRADE). GRADE is a well-accepted rating of evidence relying on expert consensus about whether new research is likely to change the confidence level (CL) of recommendations (adapted from [43]).

\begin{tabular}{|c|c|c|}
\hline Intervention & Recommendation & Strength of recommendation \\
\hline Colonoscopy & $\begin{array}{l}\text { Every } 1 \text { to } 2 \text { years beginning at age } 20 \text { to } \\
25 \text { or } \\
2 \text { to } 5 \text { years younger than youngest age at } \\
\text { diagnosis of colorectal carcinoma in } \\
\text { family if diagnosis before age } 25 \text {. } \\
\text { Considerations: start at age } 30 \text { in MSH6 } \\
\text { and age } 35 \text { in PMS2 families } \\
\text { Annual colonoscopy in MMR mutation } \\
\text { carriers }\end{array}$ & $\begin{array}{l}\text { Strong recommendation: } \\
\text { Level of evidence (III): well-designed and } \\
\text { conducted cohort or case-controlled } \\
\text { studies from more than } 1 \text { group with } \\
\text { cancer } \\
\text { \#GRADE rating: moderate }\end{array}$ \\
\hline $\begin{array}{l}\text { Pelvic examination with } \\
\text { endometrial sampling }\end{array}$ & Annually beginning at age 30 to 35 & $\begin{array}{l}\text { Offer to patient: } \\
\text { Level of evidence }(\mathrm{V}) \text { : expert consensus } \\
\text { \#GRADE rating: low }\end{array}$ \\
\hline Transvaginal ultrasound & Annually beginning at age 30 to 35 & $\begin{array}{l}\text { Offer to patient: } \\
\text { Level of evidence }(\mathrm{V}) \text { : expert consensus } \\
\text { \#GRADE rating: low }\end{array}$ \\
\hline $\begin{array}{l}\text { Esophagogastroduodenoscopy } \\
\text { with biopsy of the gastric antrum }\end{array}$ & $\begin{array}{l}\text { Beginning at age } 30 \text { to } 35 \text { and subsequent } \\
\text { surveillance every } 2 \text { to } 3 \text { years can be } \\
\text { considered based on patient risk factors }\end{array}$ & $\begin{array}{l}\text { Offer to patient: } \\
\text { Level of evidence }(\mathrm{V}) \text { : expert consensus } \\
\text { \#GRADE rating: low }\end{array}$ \\
\hline Urinalysis & Annually beginning at age 30 to 35 & $\begin{array}{l}\text { Consideration: } \\
\text { Level of evidence (V): expert consensus } \\
\text { \#GRADE rating: low }\end{array}$ \\
\hline
\end{tabular}

unless specifically asked [83]. It is important to be vigilant for new onset skin lesions in patients with a previous history of endometrial carcinoma. For patients who have never been tested for LS, these skin lesions may indicate the need to testing. In such instances, the patient's original endometrial tumor tissue blocks can be used for IHC or MSI analysis testing.

Endometrial carcinoma is not the most common visceral tumor to be associated with MTS. However, there have been early case reports in the literature clearly documenting endometrial carcinomas presenting as the sentinel tumor in a few patients with MTS $[84,85]$. An old meta-analysis study uncovered 120 patients reported in the literature to have had internal malignancies, of whom seven patients were noted to have been diagnosed with endometrial carcinoma [86]. Colorectal carcinoma was shown to afflict almost half of all MTS patients with internal malignancies and a quarter was reported to have genitourinary tract malignancies [86].

In a similar vein to colorectal and endometrial carcinomas, IHC markers have been proposed as part of the workup to identify patients presenting with sebaceous neoplasms requiring confirmatory DNA MMR gene mutational analysis [83, 87-89]. More recent studies have shown IHC to be less reliable when performed on sebaceous neoplasms that are on colon or endometrial carcinomas $[89,90]$. IHC has been shown to have an unacceptably high false-positive rate of $52 \%$ with a positive predictive value (PPV) of $22 \%$ and negative predictive value (NPV) of 95\% [90]. Variable results within individual patients with multiple sebaceous neoplasms have also been demonstrated [90]. Despite the pitfalls, some center may still opt to perform IHC on sebaceous neoplasms [89]. Individuals with germline MSH6 mutations are associated with higher risk of developing endometrial carcinomas $[23,24]$ and generally do not conform to the classic LS presentation with personal and family histories of youngonset colorectal cancer [37]. MSH6 germline mutations are not uncommon in MTS patients [89, 90]. Selected IHC testing prompted by clinical history may potentially result in the missed the opportunity of identifying MTS patients harboring mutations in the MSH6 gene.

\section{PTEN}

\subsection{Cowden Syndrome}

3.1.1. Background. Cowden syndrome (CS) is an autosomal dominant syndrome with incomplete penetrance and variable expressivity characterized by multiple hamartomas, skin lesions, abnormal CNS lesions, and an increased risk of developing carcinomas in the breast, endometrium, thyroid, and genitourinary tract $[4,91]$. CS is due to germline mutations in the phosphatase and tensin homologue (PTEN) gene located on chromosome 10q23.3 [92]. The incidence of CS in the general population is difficult to ascertain due to the variable and often subtle expression resulting in difficulty in diagnosing proband patients. A clinical epidemiological study utilizing confirmatory PTEN gene mutation analysis suggests a prevalence of between 1 in 200,000 and 1 in 250,000 [93] but is likely an underestimation [94]. PTEN is a tumor suppressor gene containing 9 exons which encodes for a 403 amino acid protein [94]. The PTEN protein plays a role in the PTEN pathway by negatively regulating the PI3K/AKT/mTOR pathway by dephosphorylating phosphatidylinositol (3,4,5-)triphosphate (PIP3) to PIP2 [94]. This 
results in a decrease in downstream PI3K kinase activity such as phosphoinositide dependent kinase 1 (PDK-1), Akt, mTOR, and ribosomal protein s6 kinase (S6K1) [95-97]. The loss or reduction of PTEN activity results in activation by phosphorylation of important cellular proteins in key signaling pathways involved in cell cycle progression, metabolism, translation, growth, migration, invasion, angiogenesis, and apoptosis [95-97].

3.1.2. Endometrial Carcinomas in Cowden Syndrome. Early tumorigenesis from benign endometrium to endometrial intraepithelial neoplasia has been shown to involve the loss of PTEN function [98, 99]. It is the most common gene mutation in endometrial carcinomas with approximately $40 \%$ reported to harbor PTEN gene somatic mutations $[98,99]$. In two separate studies, between $16 \%$ and $17 \%$ of women with endometrial carcinomas who fulfill the clinical diagnostic criteria for CS have been shown to carry the deleterious germline PTEN mutations [100, 101].

Endometrial carcinoma is considered as one of the major criteria by NCCN for the diagnosis of CS. The lifetime risk of CS patients with PTEN germline mutation developing endometrial carcinomas is between $13 \%$ and $19 \%$, which is a substantially higher lifetime risk of the general population estimated to be between $2 \%$ and 4\% [102-105]. Among female individuals with CS, $12 \%$ will present to an oncology department with endometrial carcinoma as their sentinel malignancy [106]. Among female CS patients previously afflicted with a malignancy, $10 \%$ were shown represent at a later date with endometrial carcinoma as their second malignancy [106]. It must be stressing that, due to the inherent rarity of CS, the syndrome itself accounts for only a minor proportion of unselected endometrial carcinomas [107]. In a study of 240 unselected endometrial carcinoma patients, no germline mutation of PTEN was discovered [107]. In a recent study, CS and CS-like patients with endometrial carcinoma were shown to be linked to mutations other than the PTEN gene [108]. In women with CS, the majority of endometrial carcinomas have been noted to occur between the ages of 30 and $50[101,109]$. However, there have been case reports of endometrial carcinomas occurring in CS patients under the age of 20, which is a highly unusual phenomenon in the general population [110-112]. These tumors have generally been endometrioid carcinomas [110-112] with one case preceded by the finding of an atypical polypoid adenomyoma in the uterine curetting [113].

The majority of reports indicate endometrioid carcinoma to be most common subtype to afflict women with CS [110113]. However, in a large prospective multicenter study involving $371 \mathrm{CS}$ and CS-like patients with endometrial carcinoma, only $42 \%$ were noted to have carcinoma of the endometrioid subtype [108]. The remaining 58\% were reported to been diagnosed with a nonendometrioid carcinoma, of which $50 \%$ were labeled as endometrial carcinoma, NOS. Serous/clear cell carcinoma (5\%), mucinous carcinoma $(0.3 \%)$, and sarcoma $(2.7 \%)$ were shown to account for the other malignancies in the nonendometrioid carcinoma group [108]. As all the patients were recruited based on an inclusion criterion of endometrial carcinoma, we assume that the sarcoma $(2.7 \%)$ stated may in fact be carcinosarcomas [108]. Carcinosarcomas are recognized under the WHO tumor classification system to be of epithelial origin containing at least an area of malignant stromal transformation [48]. Unfortunately, the study was limited by the lack of central pathology review and we are therefore unable to use the reported histology subtypes to help guide clinical risk assessment for germline PTEN mutations. We hope that future studies will address this issue.

In addition to endometrial carcinoma, CS patients are also predisposed to uterine leiomyomata, benign ovarian cysts, and functional menstrual abnormalities [114, 115].

3.1.3. Identification of Individuals with Cowden Syndrome. Clinical criteria remain the bedrock of identifying and diagnosing CS. The latest diagnostic criteria incorporating pathognomonic features with major and minor indications have been outlined by the 2014 NCCN [116]. A suggested workup for suspected individuals can be found in Table 3. Validated pediatric and adult risk calculators to determine the risk of an individual harboring PTEN gene mutations have been made freely available online (http://www.lerner.ccf.org/ gmi/ccscore/) [101].

\subsubsection{Clinicopathological Features of Cowden Syndrome}

(1) Other Malignant Manifestations Seen in Individuals with CS. The lifetime risk for breast carcinoma among patients with CS is between 25\% and 50\% [117]. Among women with CS presenting with breast carcinoma, $48 \%$ present with it as their first malignancy and of this group, and 22\% are likely to represent with at a later date with a new primary breast carcinoma [106]. Histologically, there is a rare but highly distinctive and striking feature of CS-associated ductal adenocarcinomas seen on microscopy as dense hyalinized collagenous stroma. When present, this distinctive stroma can be seen enveloping the malignant cells [118]. The second most common malignancy among CS patients is thyroid carcinoma, with a reported lifetime risk of between 3 and $10 \%$ [119]. Thyroid carcinoma is the initial presenting tumor in $11 \%$ of CS patients [106] with an overrepresentation of follicular histology compared to the general populations [119]. Other malignancies such as renal cell carcinoma, melanoma, and colorectal and gastric carcinoma may occur $[101,103,120,121]$. One study showed colorectal carcinoma to be present in $13 \%$ of CS patients, all of whom were $<50$ years at the time of diagnosis [120].

(2) Benign Entities Seen in Individuals with CS. The most characteristic benign lesion in CS is mucocutaneous hamartomas which can present at birth and, typically, by adulthood [115, 122-124]. Hamartomatous ganglioneuromatous, adenomatous, or hyperplastic polyps involving the gastrointestinal tract simply seen as polyps on endoscopy are another common finding affecting between $35 \%$ and $85 \%$ of CS patients $[114,120,125-129]$. Other benign lesions are gastritis and the stigmata of CS, esophageal glycogenic acanthosis [120, 128]. Benign thyroid lesions are also a common feature [119, 130, 131]. Meanwhile, CS patients often present with benign 
breast lesions ranging from fibrocystic breast disease to a characteristic mammary hamartoma-like lesion with densely hyalinised collagen $[118,132]$. These lesions have a propensity to be multiple and bilateral [118]. Rarely, the lesion may be so extensive as to diffusely replace most of the normal breast tissue [118]. Identification of such lesion on histology should prompt the pathologist to inform the breast surgeon to clinically assess the patient for CS. This is especially pertinent if the patient presents with the mammary hamartomatous lesion and has yet to develop breast carcinoma. The pathognomonic lesion of CS is adult Lhermitte-Duclos disease, a slow growing hamartomatous outgrowth of the cerebellum $[133,134]$.

\subsubsection{Ancillary Laboratory Tests}

(1) Immunohistochemistry (IHC). To date, only the PTEN IHC clone $6 \mathrm{H} 2.1$ by Dako has been shown to provide reproducible staining results with good kappa scores among pathologists assessing endometrial carcinomas to determine patients' eligibility for targeted chemotherapy [135-138]. Djordjevic et al. [137] showed PTEN protein IHC marker to be lost in $64 \%$ endometrial carcinomas, of which only $67 \%$ of these were subsequently proven to contain PTEN mutations. This study did not determine if the PTEN gene mutations identified were somatic or germline [138]. Hence, it can be inferred that PTEN protein IHC if used to identify patients requiring confirmatory gene mutational analysis for CS will result in a high level of false positives and, clinically, is not useful for the identification of patients at risk of CS.

(2) Confirmatory Gene Mutational Analysis. The majority of patients meeting the guidelines for the diagnosis of CS have a mutation of the PTEN gene (up to $80 \%$ ) but the figure is lower when patients are referred from the community (approximately 25\%) [101]. Germline mutations are seen throughout the 9 exons of the PTEN gene but most appear to cluster on exon 5 [139-144]. It has been shown that de novo PTEN mutations are found in approximately $40 \%$ of proband patients who fulfill the criteria of possibly harboring the PTEN gene mutation [145]. Mutations in genes such as $S D B H-D$ and $K L L N$ which can result in similar disruption to the PTEN gene are also seen in some CS patients [108, $119,146]$. These genetic and epigenetic factors can serve as phenotypic modifiers.

3.1.6. Recommended Surveillance and Management. Current recommendations are highlighted in Table 5.

The 2014 NCCN guidelines currently indicate that women with CS aged 30-35 should be considered for annual random endometrial biopsies and/or ultrasound on an individual basis. These women must be educated on the need to respond to promptly symptoms [116]. The statement on the consideration of enrollment in a clinical trial to determine effectiveness and necessity of screening has been omitted [116]. The 2014 NCCN guidelines also suggest that riskreducing hysterectomy is discussed as an option on a case-bycase basis [116]. However, in view of reports of endometrial carcinoma presenting even in adolescence with CS, any abnormal uterine bleeding should be an indication for an endometrial biopsy in all CS patients.

\section{BRCA}

\subsection{Is Uterine Serous Carcinoma Part of the Spectrum of Hereditary Breast and Ovarian Carcinoma Syndrome?}

4.1.1. Background. Women with germline mutations in $B R C A 1$ and BRCA2 genes have an increased lifetime risk of developing breast (40\%-85\%) and ovarian (10-39\%) carcinomas [147]. Additionally, germline BRCA1/2 mutations have also been associated with carcinomas of the fallopian tube, colon, melanoma, and pancreas [148-151].

$B R C A 1$ or $B R C A 2$ genes play a crucial role in maintaining the integrity of the genome via repair of DNA double stranded breaks using the homologous recombination pathways [152]. BRCA1 and BRCA2 proteins link with RAD51 at damaged DNA and recombination sites [153]. Cells with mutations in either $B R C A$ gene result in hypersensitivity to crosslinkage agents such as cisplatin or poly (ADPribose) polymerase (PARP) inhibitors which produce double stranded breaks [154-156].

4.1.2. Evidence for Inclusion of Uterine Serous Carcinoma as Part of the Spectrum of Hereditary Breast and Ovarian Carcinoma Syndrome. Uterine serous carcinoma (USC) is a high grade variant of endometrial carcinoma $[157,158]$. It accounts for $10 \%$ of all endometrial carcinomas [159]. USC is an aggressive disease usually seen in older women with low estrogen states and is usually associated with widespread peritoneal involvement, advanced stage at initial presentation, and, prior to the introduction of platinum therapy, dismal survival rates $[159,160]$. It shares similar prognosis and identical histological features with high grade serous carcinomas of the ovary and primary peritoneum [161]. Further evidence suggesting a possible underlying difference in biology special to USC was the finding of a higher incidence of subsequent breast cancer in women with USC compared to endometrioid endometrial carcinoma (25\% versus 3.2\%, resp., $P<0.001$ ) [162].

Although USC is not currently recognized as a feature of any hereditary cancer syndrome, there have been previous speculations on its possible association with $\mathrm{HBOC}$ syndrome. It has previously been demonstrated that not only do serous carcinomas of the fallopian tube, uterus, and ovary resemble one another in histology and clinical behavior, comparative genomic hybridization has been shown to have strikingly similar mutations [163]. The endometrial carcinoma genomic characteristics published by the Tumor Cancer Genome Atlas (TCGA) also provide data to suggest a link between USC and serous carcinomas of the ovary [164]. Interestingly, recent evidence suggests most serous cell carcinoma of the ovarian carcinomas very likely arise from the epithelium fallopian tube which has undergone malignant transformation $[165,166]$. Further support for this notion is the observation that USC responds to therapeutic agents used for ovarian and peritoneal serous carcinomas [160]. 
TABLE 5: Recommendations for diagnostic workup and cancer surveillance in patients with PTEN mutations. (Adapted from [44]).

\begin{tabular}{|c|c|c|c|}
\hline & Paediatric ( $<18$ years $)$ & Adult female & Adult male \\
\hline Baseline workup & $\begin{array}{l}\text { (i) Targeted history and } \\
\text { physical examination } \\
\text { (ii) Baseline thyroid } \\
\text { ultrasound } \\
\text { (iii) Dermatologic } \\
\text { examination } \\
\text { (iv) Formal neurologic and } \\
\text { psychological testing }\end{array}$ & $\begin{array}{l}\text { (i) Targeted history and } \\
\text { physical examination } \\
\text { (ii) Baseline thyroid } \\
\text { ultrasound } \\
\text { (iii) Dermatologic } \\
\text { examination }\end{array}$ & $\begin{array}{l}\text { (i) Targeted history and } \\
\text { physical examination } \\
\text { (ii) Baseline thyroid } \\
\text { ultrasound } \\
\text { (iii) Dermatologic } \\
\text { examination }\end{array}$ \\
\hline \multicolumn{4}{|l|}{ Cancer surveillance } \\
\hline From diagnosis & $\begin{array}{l}\text { (i) Annual thyroid } \\
\text { ultrasound } \\
\text { (ii) Skin examination }\end{array}$ & $\begin{array}{l}\text { (i) Annual thyroid } \\
\text { ultrasound } \\
\text { (ii) Skin examination }\end{array}$ & $\begin{array}{l}\text { (i) Annual thyroid } \\
\text { ultrasound } \\
\text { (ii) Skin examination }\end{array}$ \\
\hline From age $30^{*}$ & $\begin{array}{l}\text { As per adult } \\
\text { recommendations }\end{array}$ & $\begin{array}{l}\text { (i) Annual mammogram } \\
\text { (for consideration of breast } \\
\text { MRI instead of } \\
\text { mammography if dense } \\
\text { breasts) } \\
\text { (ii) Annual endometrial } \\
\text { sampling or transvaginal } \\
\text { ultrasound (or from } 5 \text { years } \\
\text { before age of earliest } \\
\text { endometrial cancer) }\end{array}$ & \\
\hline From age $40^{*}$ & $\begin{array}{l}\text { As per adult } \\
\text { recommendations }\end{array}$ & $\begin{array}{l}\text { (i) Biannual colonoscopy }{ }^{* *} \\
\text { (ii) Biannual renal } \\
\text { ultrasound/MRI }\end{array}$ & $\begin{array}{l}\text { (i) Biannual colonoscopy** } \\
\text { (ii) Biannual renal } \\
\text { ultrasound/MRI }\end{array}$ \\
\hline Prophylactic surgery & Nil. & & \\
\hline
\end{tabular}

A case report in 1999 documented two Ashkenazi Jewish sisters, where one sister presented with postmenopausal USC followed by the other sister with ovarian serous carcinoma [167]. Both were later found to harbor one of the BRCA1 founder mutations. This resulted in the postulation of a possible connection between USC and HBOC syndrome [167]. Following on to this, other studies have gone on to investigate this link with varying results [168-174] with all but one [174] concentrating either mainly or solely on sequencing for the founder mutations found in Ashkenazi Jews. A large Israeli study of 199 endometrial carcinoma Ashkenazi Jewish patients, mostly with endometrioid carcinoma, was negative for BRCA1/2 mutations [169]. Seventeen patients in this study had been diagnosed with USC. Subsequent to this, four other studies involving only Jewish patients with USC found an increased mutation rate in BRCA1 between $14 \%$ and $27 \%$ [170-173] which is significantly higher than the $2.3 \%$ mutation rate in Israeli population [175]. Between $50 \%$ and $100 \%$ of these patients with $B R C A 1 / 2$ mutations either had a personal history of breast carcinoma or at least a first degree relative with breast carcinoma or ovarian carcinoma [170-173].

However, a Canadian study involving 56 non-Jewish women with USC failed to detect any of the four commonest BRCA1 or BRCA2 mutations, of which three are founder mutations in Ashkenazi Jews [168]. A recent study involving 151 non-Jewish patients with USC found the frequency of
BRCA1 germline mutations to be $2 \%$ compared to the general non-Ashkenazi American population of $0.06 \%[174,176]$. A comprehensive search for all classes of BRCA1/2 mutations was performed using the BROCA panel. Interestingly, 36 other patients had nondeleterious or variants of unknown significant mutations, 12 of which are reported as benign on the Breast Cancer Information Core database (BIC). It would be important that as longitudinal studies of patients with BRCA mutations mature it will help clarify if USC is truly a $B R C A$-related tumor.

4.1.3. Recommended Surveillance. Current surveillance guidelines are described in Table 6.

Risk reducing surgeries have led to cancer specific survival benefit as well as a reduction in all causes of mortality [177] but remain unclear if patients electing for risk reducing salpingo-oophorectomy should have concurrent opportunistic hysterectomy. However, in view of the rarity of USC as a whole, the absolute risk of developing it is likely to be small. It does not seem warranted at this point to recommend for women to undergo hysterectomy as part of primary prevention of BRCA-associated USC. However, other more crucial issues as indicated by the recent findings in the GOG-0199 study suggest postmenopausal age, abnormal transvaginal ovarian ultrasound findings and elevated serum CA-125 are associated with elevated risk of harboring invasive 
TABLE 6: Recommended surveillance and management of individuals with hereditary breast and ovarian carcinoma syndrome family members (from [45]).

Women

(i) Breast awareness (periodic and consistent breast self-exam) starting at age 18.

(ii) Clinical breast exam, every 6 to 12 months, starting at age 25 .

(iii) Breast screening

(a) Age 25-29, annual MRI screening (preferred) or mammogram if MRI is unavailable based on earliest age of onset in family.

(b) Age $>30$ to 75 , annual mammogram and breast MRI screening.

(c) Age $>75$, management should be considered on an individual basis.

(iv) Discuss the option of risk reducing mastectomy

(a) Counseling may include a discussion regarding degree of protection, reconstruction options, and risk.

(v) Recommend risk-reducing salpingo-oophorectomy, ideally between 35 and 40 years of age and upon completion of child bearing or individualized based on earliest age of onset of ovarian carcinoma in the family.

(a) Counseling includes a discussion of reproductive desires, extent of cancer risk, degree of protection for breast and ovarian cancer, management of menopausal symptoms, possible short term hormone replacement therapy (HRT) to recommend maximum age of natural menopause, and related medical issues.

(vi) Address psychological, social, and quality-of-life aspects of undergoing risk-reducing mastectomy and/or salpingo-oophorectomy. (vii) For those patients who have not elected risk-reducing salpingo-oophorectomy, consider transvaginal ultrasound (preferably day 1 to day 10 of menstrual cycle in premenopausal women) and CA-125 (preferably after day 5 of menstrual cycle in premenopausal women), every 6 months starting at age 30 or 5 to 10 years before earliest age of first diagnosis of ovarian cancer in the family.

(viii) Consider chemoprevention options for breast and ovarian cancer, including risks and benefits.

(ix) Consider investigational imaging and screening studies, when available (e.g., novel imaging technologies and more frequent screening intervals) in the context of a clinical trial.

Men

(i) Breast self-exam training and education starting at age 35 .

(ii) Clinical breast exam every 6 to 12 months, starting at age 25 .

(iii) Consider baseline mammogram at age 40; annual mammogram if gynaecomastia or parenchyma/glandular breast density on baseline study.

(iv) Starting at age 40 :

(a) Recommend prostate cancer screening for BRCA2 carriers.

(b) Consider prostate cancer screening for BRCA1 carriers.

Men and women

(i) Education regarding signs and symptoms of cancer(s), especially those associated with BRCA gene mutations.

Risk to relatives

(i) Advise about possible inherited cancer risk to relatives, options for risk assessment, and management.

(ii) Recommend genetic counseling and consideration of genetic testing for at-risk relatives.

Reproductive options

(i) For couples expressing the desire that their offspring not carry a familial BRCA mutation, advise about options for prenatal diagnosis and assisted reproduction, including preimplantation genetic diagnosis. Discussion should include known risks, limitations, and benefits of these technologies.

(ii) For BRCA2 mutation carriers, there is a risk of a rare (recessive) Fanconi anaemia/brain tumor phenotypes in offspring if both partners carry a BRCA2 mutation should be discussed.

serous carcinoma in fallopian tube, ovary, and peritoneum or serous tubal intraepithelial carcinoma (STIC) in the fallopian tube of asymptomatic patients with deleterious $B R C A 1 / 2$ gene mutations [177]. Not to be taken lightly is also the host of psychological issues faced by such patients [178]. These need to be taken into account when arriving at a clinical decision if such women should be advised to have a hysterectomy and possibly bilateral salpingo-oophorectomy.

\section{Conclusion}

Endometrial carcinomas can be the first presentation of an underlying hereditary cancer syndrome. Endometrial carcinoma can arise in patients with LS and in lesser known conditions such as MTS, CS, and possibly HBOC. Clinicians and pathologists alike play vital roles in identifying who may require genetic testing by better understanding the associated 
malignant and nonmalignant features of these conditions and the pitfalls of existing diagnostic tests. To better understand how best to screen these high-risk patients for endometrial carcinomas, we will need further research.

\section{Conflict of Interests}

The authors declare that there is no conflict of interests regarding the publication of this paper.

\section{References}

[1] J. M. Hall, M. K. Lee, B. Newman et al., "Linkage of early-onset familial breast cancer to chromosome 17q21," Science, vol. 250, no. 4988, pp. 1684-1689, 1990.

[2] L. S. Friedman, E. A. Ostermeyer, C. I. Szabo et al., "Confirmation of $B R C A 1$ by analysis of germline mutations linked to breast and ovarian cancer in ten families," Nature Genetics, vol. 8, no. 4, pp. 399-404, 1994.

[3] Y. Ionov, M. A. Peinado, S. Malkhosyan, D. Shibata, and M. Perucho, "Ubiquitous somatic mutations in simple repeated sequences reveal a new mechanism for colonic carcinogenesis," Nature, vol. 363, no. 6429, pp. 558-561, 1993.

[4] M. R. Nelen, G. W. Padberg, E. A. J. Peeters et al., "Localization of the gene for Cowden disease to chromosome 10q22-23," Nature Genetics, vol. 13, no. 1, pp. 114-116, 1996.

[5] A. Jemal, F. Bray, M. M. Center, J. Ferlay, E. Ward, and D. Forman, "Global cancer statistics," CA: A Cancer Journal for Clinicians, vol. 61, no. 2, pp. 69-90, 2011.

[6] R. Nagy, K. Sweet, and C. Eng, "Highly penetrant hereditary cancer syndromes," Oncogene, vol. 23, no. 38, pp. 6445-6470, 2004.

[7] Z. Ketabi, A.-M. Gerdes, B. Mosgaard, S. Ladelund, and I. Bernstein, "The results of gynecologic surveillance in families with hereditary nonpolyposis colorectal cancer," Gynecologic Oncology, vol. 133, no. 3, pp. 526-530, 2014.

[8] J. L. Mester, R. A. Moore, and C. Eng, "PTEN germline mutations in patients initially tested for other hereditary cancer syndromes: would use of risk assessment tools reduce genetic testing?" Oncologist, vol. 18, no. 10, pp. 1083-1090, 2013.

[9] J. M. Lancaster, C. B. Powell, L. M. Chen, and D. L. Richardson, "Statement on risk assessment for inherited gynecologic cancer predispositions," Gynecologic Oncology, 2014.

[10] W. Kohlmann and S. B. Gruber, "Lynch syndrome," in GeneRe$\operatorname{views}(R)$, R. A. Pagon, M. P. Adam, H. H. Ardinger et al., Eds., University of Washington, Seattle University of Washington, Seattle, Wash, USA, 1993.

[11] H. T. Lynch and T. C. Smyrk, "Hereditary colorectal cancer," Seminars in Oncology, vol. 26, no. 5, pp. 478-484, 1999.

[12] C. R. Boland and M. Shike, "Report from the Jerusalem workshop on Lynch syndrome-hereditary nonpolyposis colorectal cancer," Gastroenterology, vol. 138, no. 7, pp. 2197.e1-2197.e7, 2010.

[13] L. A. Loeb, "Microsatellite instability: marker of a mutator phenotype in cancer," Cancer Research, vol. 54, no. 19, pp. 5059$5063,1994$.

[14] H. F. A. Vasen, Y. Hendriks, A. E. de Jong et al., "Identification of HNPCC by molecular analysis of colorectal and endometrial tumors," Disease Markers, vol. 20, no. 4-5, pp. 207-213, 2004.
[15] S. B. Simpkins, T. Bocker, E. M. Swisher et al., "MLH1 promoter methylation and gene silencing is the primary cause of microsatellite instability in sporadic endometrial cancers," Human Molecular Genetics, vol. 8, no. 4, pp. 661-666, 1999.

[16] M. B. Loughrey, P. M. Waring, A. Tan et al., "Incorporation of somatic BRAF mutation testing into an algorithm for the investigation of hereditary non-polyposis colorectal cancer," Familial Cancer, vol. 6, no. 3, pp. 301-310, 2007.

[17] L. M. Peterson, B. R. Kipp, K. C. Halling et al., "Molecular characterization of endometrial cancer: a correlative study assessing microsatellite instability, MLH1 hypermethylation, DNA mismatch repair protein expression, and PTEN, PIK3CA, KRAS, and BRAF mutation analysis," International Journal of Gynecological Pathology, vol. 31, no. 3, pp. 195-205, 2012.

[18] R. P. Kuiper, L. E. L. M. Vissers, R. Venkatachalam et al., "Recurrence and variability of germline EPCAM deletions in Lynch syndrome," Human Mutation, vol. 32, no. 4, pp. 407-414, 2011.

[19] M. Aarnio, R. Sankila, E. Pukkala et al., "Cancer risk in mutation carriers of DNA-mismatch-repair genes," International Journal of Cancer, vol. 81, no. 2, pp. 214-218, 1999.

[20] H. Hampel, W. Frankel, J. Panescu et al., "Screening for Lynch syndrome (hereditary nonpolyposis colorectal cancer) among endometrial cancer patients," Cancer Research, vol. 66, no. 15, pp. 7810-7817, 2006.

[21] C. H. M. Leenen, M. G. F. Van Lier, H. C. Van Doorn et al., "Prospective evaluation of molecular screening for Lynch syndrome in patients with endometrial cancer $\leq 70$ years," Gynecologic Oncology, vol. 125, no. 2, pp. 414-420, 2012.

[22] K. H. Lu, M. Dinh, W. Kohlmann et al., "Gynecologic cancer as a "sentinel cancer" for women with hereditary nonpolyposis colorectal cancer syndrome," Obstetrics and Gynecology, vol. 105, no. 3, pp. 569-574, 2005.

[23] M. Miyaki, M. Konishi, K. Tanaka et al., "Germline mutation of MSH6 as the cause of hereditary nonpolyposis colorectal cancer," Nature Genetics, vol. 17, no. 3, pp. 271-272, 1997.

[24] J. Wijnen, W. de Leeuw, H. Vasen et al., "Familial endometrial cancer in female carriers of MSH6 germline mutations," Nature Genetics, vol. 23, no. 2, pp. 142-144, 1999.

[25] J. G. Dowty, A. K. Win, D. D. Buchanan et al., "Cancer risks for MLH1 and MSH2 mutation carriers," Human Mutation, vol. 34, no. 3, pp. 490-497, 2013.

[26] L. Senter, M. Clendenning, K. Sotamaa et al., "The clinical phenotype of Lynch syndrome due to germ-line PMS2 mutations," Gastroenterology, vol. 135, no. 2, pp. 419.el-428.el, 2008.

[27] A. K. Win, N. M. Lindor, I. Winship et al., "Risks of colorectal and other cancers after endometrial cancer for women with lynch syndrome," Journal of the National Cancer Institute, vol. 105, no. 4, pp. 274-279, 2013.

[28] A. Umar, C. R. Boland, J. P. Terdiman et al., "Revised Bethesda Guidelines for hereditary nonpolyposis colorectal cancer (Lynch syndrome) and microsatellite instability," Journal of the National Cancer Institute, vol. 96, no. 4, pp. 261-268, 2004.

[29] W. Sjursen, B. I. Haukanes, E. M. Grindedal et al., "Current clinical criteria for Lynch syndrome are not sensitive enough to identify MSH6 mutation carriers," Journal of Medical Genetics, vol. 47, no. 9, pp. 579-585, 2010.

[30] J. C. Strafford, "Genetic testing for lynch syndrome, an inherited cancer of the bowel, endometrium, and ovary," Reviews in Obstetrics \& Gynecology, vol. 5, no. 1, pp. 42-49, 2012. 
[31] C. S. Walsh, A. Blum, A. Walts et al., "Lynch syndrome among gynecologic oncology patients meeting Bethesda guidelines for screening," Gynecologic Oncology, vol. 116, no. 3, pp. 516-521, 2010.

[32] C. J. Pouchet, N. Wong, G. Chong et al., "A comparison of models used to predict MLH1, MSH2 and MSH6 mutation carriers," Annals of Oncology, vol. 20, no. 4, pp. 681-688, 2009.

[33] R. C. Mercado, H. Hampel, F. Kastrinos et al., "Perfor-

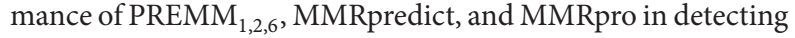
Lynch syndrome among endometrial cancer cases," Genetics in Medicine, vol. 14, no. 7, pp. 670-680, 2012.

[34] A. O. Berg, K. Armstrong, J. Botkin et al., "Recommendations from the EGAPP Working Group: genetic testing strategies in newly diagnosed individuals with colorectal cancer aimed at reducing morbidity and mortality from Lynch syndrome in relatives," Genetics in Medicine, vol. 11, no. 1, pp. 35-41, 2009.

[35] G. E. Palomaki, M. R. McClain, S. Melillo, H. L. Hampel, and S. N. Thibodeau, "EGAPP supplementary evidence review: DNA testing strategies aimed at reducing morbidity and mortality from Lynch syndrome," Genetics in Medicine, vol. 11, no. 1, pp. 42-65, 2009.

[36] J. M. Lancaster, C. Bethan Powell, N. D. Kauff et al., "Society of Gynecologic Oncologists Education Committee statement on risk assessment for inherited gynecologic cancer predispositions," Gynecologic Oncology, vol. 107, no. 2, pp. 159-162, 2007.

[37] V. Bonadona, B. Bonaïti, S. Olschwang et al., "Cancer risks associated with germline mutations in $M L H 1, M S H 2$, and MSH6 genes in lynch syndrome," The Journal of the American Medical Association, vol. 305, no. 22, pp. 2304-2310, 2011.

[38] S. N. Westin, R. A. Lacour, D. L. Urbauer et al., "Carcinoma of the lower uterine segment: a newly described association with Lynch syndrome," Journal of Clinical Oncology, vol. 26, no. 36, pp. 5965-5971, 2008.

[39] R. R. Broaddus, H. T. Lynch, L.-M. Chen et al., "Pathologic features of endometrial carcinoma associated with HNPCC: a comparison with sporadic endometrial carcinoma," Cancer, vol. 106, no. 1, pp. 87-94, 2006.

[40] M. L. Carcangiu, P. Radice, P. Casalini, L. Bertario, M. Merola, and P. Sala, "Lynch syndrome-related endometrial carcinomas show a high frequency of nonendometrioid types and of high FIGO grade endometrioid types," International Journal of Surgical Pathology, vol. 18, no. 1, pp. 21-26, 2010.

[41] L. J. Tafe, K. Garg, I. Chew, C. Tornos, and R. A. Soslow, "Endometrial and ovarian carcinomas with undifferentiated components: clinically aggressive and frequently underrecognized neoplasms," Modern Pathology, vol. 23, no. 6, pp. 781-789, 2010.

[42] R. A. Soslow, "Endometrial carcinomas with ambiguous features," Seminars in Diagnostic Pathology, vol. 27, no. 4, pp. 261273,2010

[43] F. M. Giardiello, J. I. Allen, J. E. Axilbund et al., "Guidelines on genetic evaluation and management of Lynch syndrome: a consensus statement by the US Multi-society Task Force on colorectal cancer," The American Journal of Gastroenterology, vol. 109, no. 8, pp. 1159-1179, 2014.

[44] M. H. Tan, J. L. Mester, J. Ngeow, L. A. Rybicki, M. S. Orloff, and C. Eng, "Lifetime cancer risks in individuals with germline PTEN mutations," Clinical Cancer Research, vol. 18, no. 2, pp. 400-407, 2012.

[45] National Comprehensive Cancer Network (NCCN) Guidelines, v.1, 2014.
[46] K. Garg, M. M. Leitao Jr., N. D. Kauff et al., "Selection of endometrial carcinomas for DNA mismatch repair protein immunohistochemistry using patient age and tumor morphology enhances detection of mismatch repair abnormalities," American Journal of Surgical Pathology, vol. 33, no. 6, pp. 925933, 2009.

[47] K. Garg, K. Shih, R. Barakat, Q. Zhou, A. Iasonos, and R. A. Soslow, "Endometrial carcinomas in women aged 40 years and younger: tumors associated with loss of DNA mismatch repair proteins comprise a distinct clinicopathologic subset," The American Journal of Surgical Pathology, vol. 33, no. 12, pp. 1869-1877, 2009.

[48] R. Zaino, S. G. Carinelli, L. H. Ellenson et al., "Epithelial tumours and precursors," in WHO Classification of Tumours of the Female Reproductive Organs, R. J. Kurman, M. L. Carcangiu, C. S. Herrington, and R. H. Young, Eds., pp. 125-135, International Agency for Research on Cancer (IARC), Lyon, France, 2014.

[49] J. Shia, D. Black, A. J. Hummer, J. Boyd, and R. A. Soslow, "Routinely assessed morphological features correlate with microsatellite instability status in endometrial cancer," Human Pathology, vol. 39, no. 1, pp. 116-125, 2008.

[50] K. C. Jensen, M. R. Mariappan, G. V. Putcha et al., "Microsatellite instability and mismatch repair protein defects in ovarian epithelial neoplasms in patients 50 years of age and younger," American Journal of Surgical Pathology, vol. 32, no. 7, pp. 10291037, 2008.

[51] Z. Ketabi, K. Bartuma, I. Bernstein et al., "Ovarian cancer linked to lynch syndrome typically presents as early-onset, non-serous epithelial tumors," Gynecologic Oncology, vol. 121, no. 3, pp. 462465, 2011.

[52] A. S. Bats, H. Roussel, C. Narjoz et al., "Microsatellite instability analysis for the screening of synchronous endometrial and ovarian cancer in lynch syndrome," Anticancer Research, vol. 33, no. 9, pp. 3977-3981, 2013.

[53] K. Resnick, J. M. Straughn Jr., F. Backes, H. Hampel, K. S. Matthews, and D. E. Cohn, "Lynch syndrome screening strategies among newly diagnosed endometrial cancer patients," Obstetrics and Gynecology, vol. 114, no. 3, pp. 530-536, 2009.

[54] A. N. Bartley, R. Luthra, D. S. Saraiya, D. L. Urbauer, and R. R. Broaddus, "Identification of cancer patients with lynch syndrome: clinically significant discordances and problems in tissue-based mismatch repair testing," Cancer Prevention Research, vol. 5, no. 2, pp. 320-327, 2012.

[55] M. Kawaguchi, M. Yanokura, K. Banno et al., "Analysis of a correlation between the BRAF V600E mutation and abnormal DNA mismatch repair in patients with sporadic endometrial cancer," International Journal of Oncology, vol. 34, no. 6, pp. 1541-1547, 2009.

[56] I. Modica, R. A. Soslow, D. Black, C. Tornos, N. Kauff, and J. Shia, "Utility of immunohistochemistry in predicting microsatellite instability in endometrial carcinoma," The American Journal of Surgical Pathology, vol. 31, no. 5, pp. 744-751, 2007.

[57] M. J. W. Berends, Y. Wu, R. H. Sijmons et al., "Molecular and clinical characteristics of MSH6 variants: an analysis of 25 index carriers of a germline variant," The American Journal of Human Genetics, vol. 70, no. 1, pp. 26-37, 2002.

[58] P. Peltomäki, "Role of DNA mismatch repair defects in the pathogenesis of human cancer," Journal of Clinical Oncology, vol. 21, no. 6, pp. 1174-1179, 2003.

[59] A. M. Bellizzi and W. L. Frankel, "Colorectal cancer due to deficiency in DNA mismatch repair function: a review," 
Advances in Anatomic Pathology, vol. 16, no. 6, pp. 405-417, 2009.

[60] S. Gill, N. M. Lindor, L. J. Burgart et al., "Isolated loss of PMS2 expression in colorectal cancers: frequency, patient age, and familial aggregation," Clinical Cancer Research, vol. 11, no. 18, pp. 6466-6471, 2005.

[61] J. Moline, H. Mahdi, B. Yang et al., "Implementation of tumor testing for lynch syndrome in endometrial cancers at a large academic medical center," Gynecologic Oncology, vol. 130, no. 1, pp. 121-126, 2013.

[62] A. Müller, G. Giuffre, T. B. Edmonston et al., "Challenges and pitfalls in HNPCC screening by microsatellite analysis and immunohistochemistry," The Journal of Molecular Diagnostics, vol. 6, no. 4, pp. 308-315, 2004.

[63] A. K. Folkins and T. A. Longacre, "Hereditary gynaecological malignancies: advances in screening and treatment," Histopathology, vol. 62, no. 1, pp. 2-30, 2013.

[64] K. Garg and R. A. Soslow, "Endometrial carcinoma in women aged 40 years and younger," Archives of Pathology \& Laboratory Medicine, vol. 138, no. 3, pp. 335-342, 2014.

[65] C. R. Boland, S. N. Thibodeau, S. R. Hamilton et al., "A National Cancer Institute workshop on microsatellite instability for cancer detection and familial predisposition: development of international criteria for the determination of microsatellite instability in colorectal cancer," Cancer Research, vol. 58, no. 22, pp. 5248-5257, 1998.

[66] O. Buhard, N. Suraweera, A. Lectard, A. Duval, and R. Hamelin, "Quasimonomorphic mononucleotide repeats for high-level microsatellite instability analysis," Disease Markers, vol. 20, no. 4-5, pp. 251-257, 2004.

[67] M. A. Rodriguez-Bigas, C. R. Boland, S. R. Hamilton et al., "A National Cancer Institute Workshop on Hereditary Nonpolyposis Colorectal Cancer Syndrome: meeting highlights and Bethesda guidelines," Journal of the National Cancer Institute, vol. 89, no. 23, pp. 1758-1762, 1997.

[68] N. Suraweera, A. Duval, M. Reperant et al., "Evaluation of tumor microsatellite instability using five quasimonomorphic mononucleotide repeats and pentaplex PCR," Gastroenterology, vol. 123, no. 6, pp. 1804-1811, 2002.

[69] J.-F. You, O. Buhard, M. J. L. Ligtenberg et al., "Tumours with loss of MSH6 expression are MSI-H when screened with a pentaplex of five mononucleotide repeats," British Journal of Cancer, vol. 103, no. 12, pp. 1840-1845, 2010.

[70] L. Zhang, "Immunohistochemistry versus microsatellite instability testing for screening colorectal cancer patients at risk for hereditary nonpolyposis colorectal cancer syndrome: part II. The utility of microsatellite instability testing," The Journal of Molecular Diagnostics, vol. 10, no. 4, pp. 301-307, 2008.

[71] F. M. Giardiello, J. I. Allen, J. E. Axilbund et al., "Guidelines on genetic evaluation and management of Lynch syndrome: a consensus statement by the US multi-society task force on colorectal cancer," Gastroenterology, vol. 147, no. 2, pp. 502-526, 2014.

[72] M. E. Kovacs, J. Papp, Z. Szentirmay, S. Otto, and E. Olah, "Deletions removing the last exon of TACSTD1 constitute a distinct class of mutations predisposing to lynch syndrome," Human Mutation, vol. 30, no. 2, pp. 197-203, 2009.

[73] M. S. Daniels, "Genetic testing by cancer site: uterus," Cancer Journal, vol. 18, no. 4, pp. 338-342, 2012.

[74] R. H. Sijmons, M. S. Greenblatt, and M. Genuardi, "Gene variants of unknown clinical significance in Lynch syndrome.
An introduction for clinicians," Familial Cancer, vol. 12, no. 2, pp. 181-187, 2013.

[75] H. Hampel, "NCCN increases the emphasis on genetic/familial high-risk assessment in colorectal cancer," Journal of the National Comprehensive Cancer Network, vol. 12, no. 5, supplement, pp. 829-831, 2014.

[76] L. H. Gerritzen, N. Hoogerbrugge, A. L. M. Oei et al., "Improvement of endometrial biopsy over transvaginal ultrasound alone for endometrial surveillance in women with Lynch syndrome," Familial Cancer, vol. 8, no. 4, pp. 391-397, 2009.

[77] D. R. Nebgen, K. H. Lu, S. Rimes et al., "Combined colonoscopy and endometrial biopsy cancer screening results in women with Lynch syndrome," vol. 135, no. 1, pp. 85-89, 2014.

[78] H. T. Lynch, P. M. Lynch, J. Pester, and R. M. Fusaro, “The cancer family syndrome. Rare cutaneous phenotypic linkage of Torre's syndrome," Archives of Internal Medicine, vol. 141, no. 5, pp. 607611, 1981.

[79] R. Kruse, A. Rütten, C. Lamberti et al., "Muir-Torre phenotype has a frequency of DNA mismatch-repair-gene mutations similar to that in hereditary nonpolyposis colorectal cancer families defined by the Amsterdam criteria," The American Journal of Human Genetics, vol. 63, no. 1, pp. 63-70, 1998.

[80] C. D. South, H. Hampel, I. Comeras, J. A. Westman, W. L. Frankel, and A. de la Chapelle, "The frequency of Muir-Torre syndrome among Lynch syndrome families," Journal of the National Cancer Institute, vol. 100, no. 4, pp. 277-281, 2008.

[81] G. Ponti and M. P. de Leon, "Muir-Torre syndrome," The Lancet Oncology, vol. 6, no. 12, pp. 980-987, 2005.

[82] S. C. Shalin, S. Lyle, E. Calonje, and A. J. F. Lazar, "Sebaceous neoplasia and the Muir-Torre syndrome: important connections with clinical implications," Histopathology, vol. 56, no. 1, pp. 133-147, 2010.

[83] O. Abbas and M. Mahalingam, "Cutaneous sebaceous neoplasms as markers of Muir-Torre syndrome: a diagnostic algorithm," Journal of Cutaneous Pathology, vol. 36, no. 6, pp. 613619, 2009.

[84] H. T. Lynch, W. A. Bardawil, R. E. Harris, P. M. Lynch, H. A. Guirgis, and J. F. Lynch, "Multiple primary cancers and prolonged survival: familial colonic and endometrial cancers," Diseases of the Colon \& Rectum, vol. 21, no. 3, pp. 165-168, 1978.

[85] T. Tohya, T. Ogura, K. Nishi, H. Nishi, and K. Kuriwaki, "MuirTorre syndrome associated with endometrial carcinoma," International Journal of Clinical Oncology, vol. 13, no. 6, pp. 559-561, 2008.

[86] P. R. Cohen, S. R. Kohn, and R. Kurzrock, "Association of sebaceous gland tumors and internal malignancy: the MuirTorre syndrome," The American Journal of Medicine, vol. 90, no. 5, pp. 606-613, 1991.

[87] B. Jones, C. Oh, E. Mangold, and C. A. Egan, "Muir-Torre syndrome: diagnostic and screening guidelines," Australasian Journal of Dermatology, vol. 47, no. 4, pp. 266-269, 2006.

[88] A. Mojtahed, I. Schrijver, J. M. Ford, T. A. Longacre, and R. K. Pai, "A two-antibody mismatch repair protein immunohistochemistry screening approach for colorectal carcinomas, skin sebaceous tumors, and gynecologic tract carcinomas," Modern Pathology, vol. 24, no. 7, pp. 1004-1014, 2011.

[89] J. N. Everett, V. M. Raymond, M. Dandapani et al., "Screening for germline mismatch repair mutations following diagnosis of sebaceous neoplasm," JAMA Dermatology, 2014.

[90] M. E. Roberts, D. L. Riegert-Johnson, B. C. Thomas et al., "Screening for Muir-Torre syndrome using mismatch repair 
protein immunohistochemistry of sebaceous neoplasms," Journal of Genetic Counseling, vol. 22, no. 3, pp. 393-405, 2013.

[91] M. A. Scheper, N. G. Nikitakis, E. Sarlani, J. J. Sauk, and T. F. Meiller, "Cowden syndrome: report of a case with immunohistochemical analysis and review of the literature," Oral Surgery, Oral Medicine, Oral Pathology, Oral Radiology and Endodontology, vol. 101, no. 5, pp. 625-631, 2006.

[92] D.-M. Li and H. Sun, "TEP1, encoded by a candidate tumor suppressor locus, is a novel protein tyrosine phosphatase regulated by transforming growth factor $\beta$," Cancer Research, vol. 57, no. 11, pp. 2124-2129, 1997.

[93] M. R. Nelen, H. Kremer, I. B. M. Konings et al., "Novel PTEN mutations in patients with Cowden disease: absence of clear genotype-phenotype correlations," European Journal of Human Genetics, vol. 7, no. 3, pp. 267-273, 1999.

[94] R. Pilarski and C. Eng, "Will the real Cowden syndrome please stand up (again)? Expanding mutational and clinical spectra of the PTEN hamartoma tumour syndrome," Journal of Medical Genetics, vol. 41, no. 5, pp. 323-326, 2004.

[95] J. Huang and C. D. Kontos, "PTEN modulates vascular endothelial growth factor-mediated signaling and angiogenic effects," The Journal of Biological Chemistry, vol. 277, no. 13, pp. 1076010766, 2002.

[96] K. A. Waite and C. Eng, "Protean PTEN: form and function," The American Journal of Human Genetics, vol. 70, no. 4, pp. 829844, 2002.

[97] J. LoPiccolo, M. S. Ballas, and P. A. Dennis, "PTEN hamartomatous tumor syndromes (PHTS): rare syndromes with great relevance to common cancers and targeted drug development," Critical Reviews in Oncology/Hematology, vol. 63, no. 3, pp. 203214, 2007.

[98] G. L. Mutter, "Histopathology of genetically defined endometrial precancers," International Journal of Gynecological Pathology, vol. 19, no. 4, pp. 301-309, 2000.

[99] G. L. Mutter, M.-C. Lin, J. T. Fitzgerald, J. B. Kum, and C. Eng, "Changes in endometrial PTEN expression throughout the human menstrual cycle," Journal of Clinical Endocrinology and Metabolism, vol. 85, no. 6, pp. 2334-2338, 2000.

[100] R. Pilarski, J. A. Stephens, R. Noss, J. L. Fisher, and T. W. Prior, "Predicting PTEN mutations: an evaluation of cowden syndrome and Bannayan-Riley-Ruvalcaba syndrome clinical features," Journal of Medical Genetics, vol. 48, no. 8, pp. 505-512, 2011.

[101] M.-H. Tan, J. Mester, C. Peterson et al., "A clinical scoring system for selection of patients for pten mutation testing is proposed on the basis of a prospective study of 3042 probands," The American Journal of Human Genetics, vol. 88, no. 1, pp. 4256, 2011.

[102] D. L. Riegert-Johnson, F. C. Gleeson, M. Roberts et al., "Cancer and Lhermitte-Duclos disease are common in Cowden syndrome patients," Hereditary Cancer in Clinical Practice, vol. 8, no. 1, article 6, 2010.

[103] M.-H. Tan, J. L. Mester, J. Ngeow, L. A. Rybicki, M. S. Orloff, and C. Eng, "Lifetime cancer risks in individuals with germline PTEN mutations," Clinical Cancer Research, vol. 18, no. 2, pp. 400-407, 2012.

[104] V. Bubien, F. Bonnet, V. Brouste et al., "High cumulative risks of cancer in patients with PTEN hamartoma tumour syndrome," Journal of Medical Genetics, vol. 50, no. 4, pp. 255-263, 2013.

[105] M. H. Nieuwenhuis, C. M. Kets, M. Murphy-Ryan et al., "Cancer risk and genotype-phenotype correlations in PTEN hamartoma tumor syndrome," Familial Cancer, vol. 13, no. 1, pp. 57-63, 2014.
[106] J. Ngeow, K. Stanuch, J. L. Mester, J. S. Barnholtz-Sloan, and C. Eng, "Second malignant neoplasms in patients with Cowden syndrome with underlying germline PTEN mutations," Journal of Clinical Oncology, vol. 32, no. 17, pp. 1818-1824, 2014.

[107] D. Black, F. Bogomolniy, M. E. Robson, K. Offit, R. R. Barakat, and J. Boyd, "Evaluation of germline PTEN mutations in endometrial cancer patients," Gynecologic Oncology, vol. 96, no. 1, pp. 21-24, 2005.

[108] H. Mahdi, J. Mester, E. A. Nizialek, J. Ngeow, C. Michener, and C. Eng, "Germline PTEN, SDHB-D, and KLLN alterations in endometrial cancer patients with cowden and cowden-like syndromes: an international, multicenter, prospective study," Cancer, 2014.

[109] T. M. Starink, J. P. van der Veen, F. Arwert et al., "The Cowden syndrome: a clinical and genetic study in 21 patients," Clinical Genetics, vol. 29, no. 3, pp. 222-233, 1986.

[110] W. D. Baker, A. P. Soisson, and M. K. Dodson, "Endometrial cancer in a 14-year-old girl with Cowden syndrome: a case report," Journal of Obstetrics and Gynaecology Research, vol. 39, no. 4, pp. 876-878, 2013.

[111] A. C. ElNaggar, S. L. Spunt, W. Smith, M. Depas, and J. T. Santoso, "Endometrial cancer in a 15-year-old girl: a complication of cowden syndrome," Gynecologic Oncology Case Reports, vol. 3, pp. 18-19, 2013.

[112] K. M. Schmeler, M. S. Daniels, A. C. Brandt, and K. H. Lu, "Endometrial cancer in an adolescent: a possible manifestation of Cowden syndrome," Obstetrics and Gynecology, vol. 114, no. 2, part 2, pp. 477-479, 2009.

[113] J. M. Edwards, S. Alsop, and S. C. Modesitt, "Coexisting atypical polypoid adenomyoma and endometrioid endometrial carcinoma in a young woman with Cowden Syndrome: case report and implications for screening and prevention," Gynecologic Oncology Case Reports, vol. 2, no. 2, pp. 29-31, 2012.

[114] O. S. Salem and W. D. Steck, "Cowden's disease (multiple hamartoma and neoplasia syndrome). A case report and review of the English literature," Journal of the American Academy of Dermatology, vol. 8, no. 5, pp. 686-696, 1983.

[115] T. M. Starink and R. Hausman, "The cutaneous pathology of extrafacial lesions in Cowden's disease," Journal of Cutaneous Pathology, vol. 11, no. 5, pp. 338-344, 1984.

[116] M. B. Daly, R. Pilarski, J. E. Axilbund et al., "Genetic/familial high-risk assessment: breast and ovarian, version 1.2014," Journal of the National Comprehensive Cancer Network, vol. 12, no. 9, pp. 1326-1338, 2014.

[117] R. Nosbaum, K. J. Vogel, and K. Ready, "Susceptibility to breast cancer: hereditary syndromes and low penetrance genes," Breast Disease, vol. 27, no. 1, pp. 21-50, 2007.

[118] C. A. Schrager, D. Schneider, A. C. Gruener, H. C. Tsou, and M. Peacocke, "Clinical and pathological features of breast disease in Cowden's syndrome: an underrecognized syndrome with an increased risk of breast cancer," Human Pathology, vol. 29, no. 1, pp. 47-53, 1998.

[119] J. Ngeow, J. Mester, L. A. Rybicki, Y. Ni, M. Milas, and C. Eng, "Incidence and clinical characteristics of thyroid cancer in prospective series of individuals with cowden and cowdenlike syndrome characterized by germline PTEN, SDH, or KLLN alterations," Journal of Clinical Endocrinology and Metabolism, vol. 96, no. 12, pp. E2063-E2071, 2011.

[120] B. Heald, J. Mester, L. Rybicki, M. S. Orloff, C. A. Burke, and C. Eng, "Frequent gastrointestinal polyps and colorectal adenocarcinomas in a prospective series of PTEN mutation carriers," Gastroenterology, vol. 139, no. 6, pp. 1927-1933, 2010. 
[121] P. P. Stanich, V. L. Owens, S. Sweetser et al., "Colonic polyposis and neoplasia in Cowden syndrome," Mayo Clinic Proceedings, vol. 86, no. 6, pp. 489-492, 2011.

[122] T. M. Starink and R. Hausman, "The cutaneous pathology of facial lesions in Cowden's disease," Journal of Cutaneous Pathology, vol. 11, no. 5, pp. 331-337, 1984.

[123] S. K. Fistarol, M. D. Anliker, and P. H. Itin, "Cowden disease or multiple hamartoma syndrome-cutaneous clue to internal malignancy," European Journal of Dermatology, vol. 12, no. 5, pp. 411-421, 2002.

[124] O. Kovich and D. Cohen, “Cowden's syndrome," Dermatology Online Journal, vol. 10, no. 3, p. 3, 2004.

[125] G. J. Carlson, S. Nivatvongs, and D. C. Snover, "Colorectal polyps in Cowden's disease (multiple hamartoma syndrome)," The American Journal of Surgical Pathology, vol. 8, no. 10, pp. 763-770, 1984.

[126] A. J. Taylor, W. J. Dodds, and E. T. Stewart, "Alimentary tract lesions in Cowden's disease," The British Journal of Radiology, vol. 62, no. 742, pp. 890-892, 1989.

[127] S. Olschwang, O. M. Serova-Sinilnikova, G. M. Lenoir, and G. Thomas, "PTEN germ-line mutations in juvenile polyposis coli," Nature Genetics, vol. 18, no. 1, pp. 12-14, 1998.

[128] R. Coriat, M. Mozer, E. Caux et al., "Endoscopic findings in Cowden syndrome," Endoscopy, vol. 43, no. 8, pp. 723-726, 2011.

[129] P. P. Stanich, R. Pilarski, J. Rock, W. L. Frankel, S. El-Dika, and M. M. Meyer, "Colonic manifestations of PTEN hamartoma tumor syndrome: case series and systematic review," World Journal of Gastroenterology, vol. 20, no. 7, pp. 1833-1838, 2014.

[130] J. A. Barletta, A. M. Bellizzi, and J. L. Hornick, "Immunohistochemical staining of thyroidectomy specimens for pten can aid in the identification of patients with cowden syndrome," The American Journal of Surgical Pathology, vol. 35, no. 10, pp. 15051511, 2011.

[131] J. E. Hall, D. J. Abdollahian, and R. J. Sinard, "Thyroid disease associated with cowden syndrome: a meta-analysis," Head and Neck, vol. 35, no. 8, pp. 1189-1194, 2013.

[132] M. H. Brownstein, M. Wolf, and J. B. Bikowski, "Cowden's disease: a cutaneous marker of breast cancer," Cancer, vol. 41, no. 6, pp. 2393-2398, 1978.

[133] F. Barone, B. A. Noubari, A. Torrisi, S. Lanzafame, R. Tropea, and P. Mancuso, "Lhermitte Duclos disease and Cowden disease: clinical, pathological and neuroimaging study of a case," Journal of Neurosurgical Sciences, vol. 44, no. 4, pp. 234-237, 2000.

[134] D. A. Nowak and H. A. Trost, "Lhermitte-Duclos disease (dysplastic cerebellar gangliocytoma): a malformation, hamartoma or neoplasm?" Acta Neurologica Scandinavica, vol. 105, no. 3, pp. 137-145, 2002.

[135] K. Garg, R. R. Broaddus, R. A. Soslow, D. L. Urbauer, D. A. Levine, and B. Djordjevic, "Pathologic scoring of PTEN immunohistochemistry in endometrial carcinoma is highly reproducible," International Journal of Gynecological Pathology, vol. 31, no. 1, pp. 48-56, 2012.

[136] O. Maiques, M. Santacana, J. Valls et al., "Optimal protocol for PTEN immunostaining; role of analytical and preanalytical variables in PTEN staining in normal and neoplastic endometrial, breast, and prostatic tissues," Human Pathology, vol. 45, no. 3, pp. 522-532, 2014.

[137] B. Djordjevic, B. T. Hennessy, J. Li et al., "Clinical assessment of PTEN loss in endometrial carcinoma: immunohistochemistry outperforms gene sequencing," Modern Pathology, vol. 25, no. 5, pp. 699-708, 2012.
[138] B. Djordjevic, B. A. Barkoh, R. Luthra, and R. R. Broaddus, "Relationship between PTEN, DNA mismatch repair, and tumor histotype in endometrial carcinoma: retained positive expression of PTEN preferentially identifies sporadic nonendometrioid carcinomas," Modern Pathology, vol. 26, no. 10, pp. 1401-1412, 2013.

[139] D. J. Marsh, J. B. Kum, K. L. Lunetta et al., "PTEN mutation spectrum and genotype-phenotype correlations in BannayanRiley-Ruvalcaba syndrome suggest a single entity with Cowden syndrome," Human Molecular Genetics, vol. 8, no. 8, pp. 1461$1472,1999$.

[140] I. de Vivo, D. M. Gertig, S. Nagase et al., "Novel germline mutations in the PTEN tumour suppressor gene found in women with multiple cancers," Journal of Medical Genetics, vol. 37, no. 5, pp. 336-341, 2000.

[141] R. E. Teresi, K. M. Zbuk, M. G. Pezzolesi, K. A. Waite, and C. Eng, "Cowden syndrome-affected patients with PTEN promoter mutations demonstrate abnormal protein translation," American Journal of Human Genetics, vol. 81, no. 4, pp. 756-767, 2007.

[142] G. Tate, T. Suzuki, Y. Endo, and T. Mitsuya, "A novel mutation of the PTEN gene in a Japanese patient with Cowden syndrome and bilateral breast cancer," Cancer Genetics and Cytogenetics, vol. 184, no. 1, pp. 67-71, 2008.

[143] X.-P. Zhou, D. J. Marsh, C. D. Morrison et al., "Germline inactivation of PTEN and dysregulation of the phosphoinositol3-kinase/Akt pathway cause human Lhermitte-Duclos disease in adults," The American Journal of Human Genetics, vol. 73, no. 5, pp. 1191-1198, 2003.

[144] J. Reifenberger, L. Rauch, M. W. Beckmann, M. Megahed, T. Ruzicka, and G. Reifenberger, “Cowden's disease: clinical and molecular genetic findings in a patient with a novel PTEN germline mutation," British Journal of Dermatology, vol. 148, no. 5, pp. 1040-1046, 2003.

[145] J. Mester and C. Eng, "Estimate of de novo mutation frequency in probands with PTEN hamartoma tumor syndrome," Genetics in Medicine, vol. 14, no. 9, pp. 819-822, 2012.

[146] E. Nizialek, C. Peterson, J. Mester, E. Downes-Kelly, and C. Eng, "Germline and somatic KLLN alterations in breast cancer dysregulate G2 arrest," Human Molecular Genetics, vol. 22, no. 12, pp. 2451-2461, 2013.

[147] V. Moyer, "Summaries for patients. Assessing the genetic risk for BRCA-related breast or ovarian cancer in women: recommendations from the U.S. Preventive Services Task Force," Annals of Internal Medicine, vol. 160, no. 4, pp. 1-16, 2014.

[148] M. S. Brose, T. R. Rebbeck, K. A. Calzone, J. E. Stopfer, K. L. Nathanson, and B. L. Weber, "Cancer risk estimates for BCRA1 mutation carriers identified in a risk evaluation program," Journal of the National Cancer Institute, vol. 94, no. 18, pp. 13651372, 2002.

[149] J. L. Bermejo and K. Hemminki, "Risk of cancer at sites other than the breast in Swedish families eligible for BRCA1 or BRCA2 mutation testing," Annals of Oncology, vol. 15, no. 12, pp. 18341841, 2004.

[150] P. L. Mai, N. Chatterjee, P. Hartge et al., "Potential excess mortality in BRCA1/2 mutation carriers beyond breast, ovarian, prostate, and pancreatic cancers and melanoma," PLOS ONE, vol. 4, no. 3, Article ID e4812, 2009.

[151] J. M. Noh, D. H. Choi, H. Baek et al., "Associations between $B R C A$ mutations in high-risk breast cancer patients and familial cancers other than breast or ovary," Journal of Breast Cancer, vol. 15 , no. 3, pp. 283-287, 2012. 
[152] K. Yoshida and Y. Miki, "Role of BRCA1 and BRCA2 as regulators of DNA repair, transcription, and cell cycle in response to DNA damage," Cancer Science, vol. 95, no. 11, pp. 866-871, 2004.

[153] P. L. Welcsh, K. N. Owens, and M.-C. King, "Insights into the functions of BRCA1 and BRCA2," Trends in Genetics, vol. 16, no. 2, pp. 69-74, 2000.

[154] T. Helleday, "The underlying mechanism for the PARP and BRCA synthetic lethality: clearing up the misunderstandings," Molecular Oncology, vol. 5, no. 4, pp. 387-393, 2011.

[155] C. C. O'Sullivan, D. H. Moon, E. C. Kohn, and J.-M. Lee, "Beyond breast and ovarian cancers: PARP inhibitors for BRCA mutation-associated and BRCA-like solid tumors," Frontiers in Oncology, vol. 4, article 42, 2014.

[156] W. R. Wiedemeyer, J. A. Beach, and B. Y. Karlan, "Reversing platinum resistance in high-grade serous ovarian carcinoma: targeting BRCA and the homologous recombination system," Frontiers in Oncology, vol. 4, article 34, 2014.

[157] S. C. Lauchlan, "Tubal (serous) carcinoma of the endometrium," Archives of Pathology and Laboratory Medicine, vol. 105, no. 11, pp. 615-618, 1981.

[158] M. Hendrickson, J. Ross, and A. Martinez, "Uterine papillary serous carcinoma: a highly malignant form of endometrial adenocarcinoma," The American Journal of Surgical Pathology, vol. 6, no. 2, pp. 93-108, 1982.

[159] S. F. Lax and R. J. Kurman, "A dualistic model for endometrial carcinogenesis based on immunohistochemical and molecular genetic analyses," Verhandlungen der Deutschen Gesellschaft für Pathologie, vol. 81, pp. 228-232, 1997.

[160] A. Jhingran, L. M. Ramondetta, D. C. Bodurka et al., "A prospective phase II study of chemoradiation followed by adjuvant chemotherapy for FIGO stage I-IIIA (1988) uterine papillary serous carcinoma of the endometrium," Gynecologic Oncology, vol. 129, no. 2, pp. 304-309, 2013.

[161] M. E. Sherman, P. Bitterman, N. B. Rosenshein, G. Delgado, and R. J. Kurman, "Uterine serous carcinoma: a morphologically diverse neoplasm with unifying clinicopathologic features," The American Journal of Surgical Pathology, vol. 16, no. 6, pp. 600610, 1992.

[162] J. P. Geisler, J. I. Sorosky, H.-L. Duong et al., "Papillary serous carcinoma of the uterus: increased risk of subsequent or concurrent development of breast carcinoma," Gynecologic Oncology, vol. 83, no. 3, pp. 501-503, 2001.

[163] H. Pere, J. Tapper, M. Seppälä, S. Knuutila, and R. Butzow, "Genomic alterations in fallopian tube carcinoma: comparison to serous uterine and ovarian carcinomas reveals similarity suggesting likeness in molecular pathogenesis," Cancer Research, vol. 58, no. 19, pp. 4274-4276, 1998.

[164] C. Kandoth, N. Schultz, A. D. Cherniack et al., "Integrated genomic characterization of endometrial carcinoma," Nature, vol. 497, no. 7447, pp. 67-73, 2013.

[165] R. Vang, I. M. Shih, and R. J. Kurman, "Fallopian tube precursors of ovarian low- and high-grade serous neoplasms," Histopathology, vol. 62, no. 1, pp. 44-58, 2013.

[166] R. J. Kurman, "Origin and molecular pathogenesis of ovarian high-grade serous carcinoma," Annals of Oncology, vol. 24, no. 10, pp. x16-x21, 2013.

[167] G. Hornreich, U. Beller, O. Lavie, P. Renbaum, Y. Cohen, and E. Levy-Lahad, "Is uterine serous papillary carcinoma a BRCA1related disease? Case report and review of the literature," Gynecologic Oncology, vol. 75, no. 2, pp. 300-304, 1999.
[168] R. Goshen, W. Chu, L. Elit et al., "Is uterine papillary serous adenocarcinoma a manifestation of the hereditary breast-ovarian cancer syndrome?" Gynecologic Oncology, vol. 79, no. 3, pp. 477481, 2000.

[169] D. A. Levine, O. Lin, R. R. Barakat et al., "Risk of endometrial carcinoma associated with BRCA mutation," Gynecologic Oncology, vol. 80, no. 3, pp. 395-398, 2001.

[170] O. Lavie, G. Hornreich, A. Ben-Arie et al., "BRCA germline mutations in Jewish women with uterine serous papillary carcinoma," Gynecologic Oncology, vol. 92, no. 2, pp. 521-524, 2004.

[171] T. Biron-Shental, L. Drucker, M. Altaras, J. Bernheim, and A. Fishman, "High incidence of BRCA1-2 germline mutations, previous breast cancer and familial cancer history in Jewish patients with uterine serous papillary carcinoma," European Journal of Surgical Oncology, vol. 32, no. 10, pp. 1097-1100, 2006.

[172] O. Lavie, A. Ben-Arie, Y. Segev et al., "BRCA germline mutations in women with uterine serous carcinoma-still a debate," International Journal of Gynecological Cancer, vol. 20, no. 9, pp. 1531-1534, 2010.

[173] I. Bruchim, K. Amichay, D. Kidron et al., "BRCA1/2 germline mutations in Jewish patients with uterine serous carcinoma," International Journal of GynecologicalCancer, vol. 20, no. 7, pp. 1148-1153, 2010.

[174] K. P. Pennington, T. Walsh, M. Lee et al., "BRCA1, TP53, and CHEK2 germline mutations in uterine serous carcinoma," Cancer, vol. 119, no. 2, pp. 332-338, 2013.

[175] B. B. Roa, A. A. Boyd, K. Volcik, and C. S. Richards, "Ashkenazi jewish population frequencies for common mutations in BRCA1 and BRCA2," Nature Genetics, vol. 14, no. 2, pp. 185-187, 1996.

[176] D. Ford, D. F. Easton, and J. Peto, "Estimates of the gene frequency of BRCA1 and its contribution to breast and ovarian cancer incidence," The American Journal of Human Genetics, vol. 57, no. 6, pp. 1457-1462, 1995.

[177] M. E. Sherman, M. Piedmonte, P. L. Mai et al., "Pathologic findings at risk-reducing salpingo-oophorectomy: primary results from gynecologic oncology group trial GOG-0199," Journal of Clinical Oncology, 2014

[178] C. Maheu, A.-D. Bouhnik, C. Nogues et al., "Which factors predict proposal and uptake of psychological counselling after BRCA1/2 test result disclosure?" Psycho-Oncology, vol. 23, no. 4, pp. $420-427,2014$. 


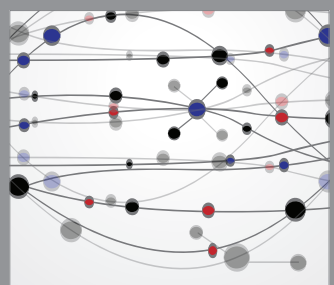

The Scientific World Journal
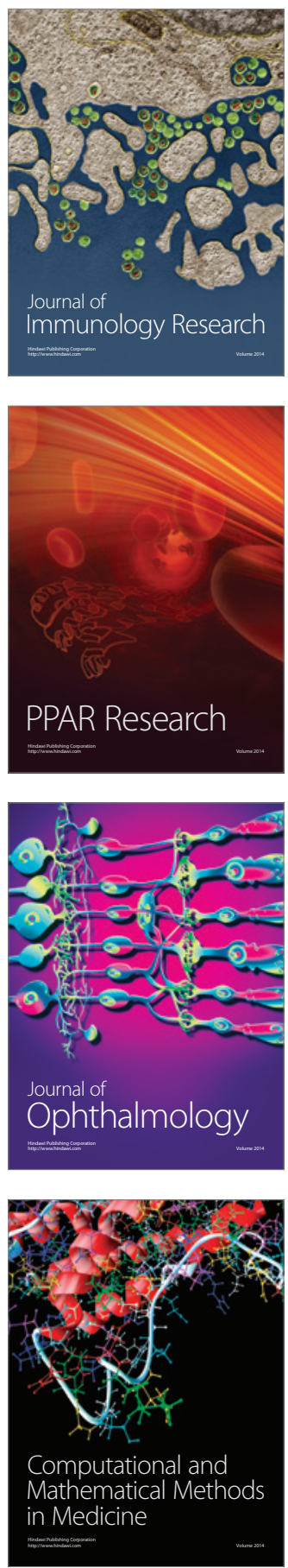

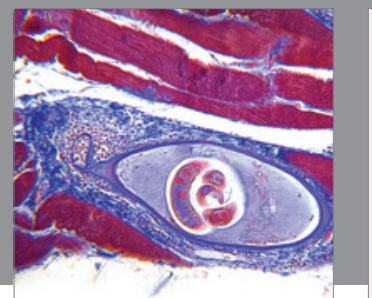

Gastroenterology

Research and Practice
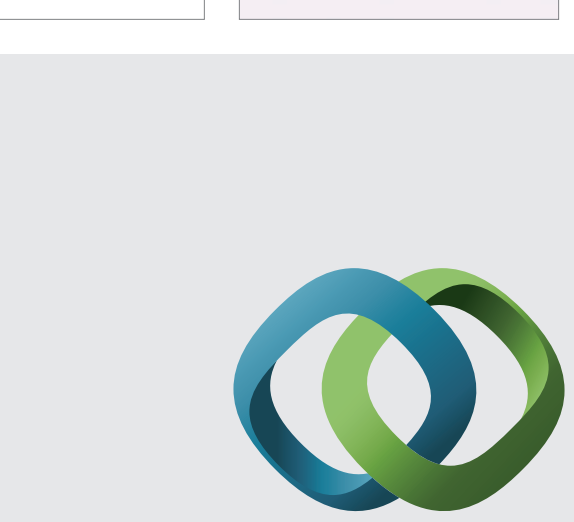

\section{Hindawi}

Submit your manuscripts at

http://www.hindawi.com
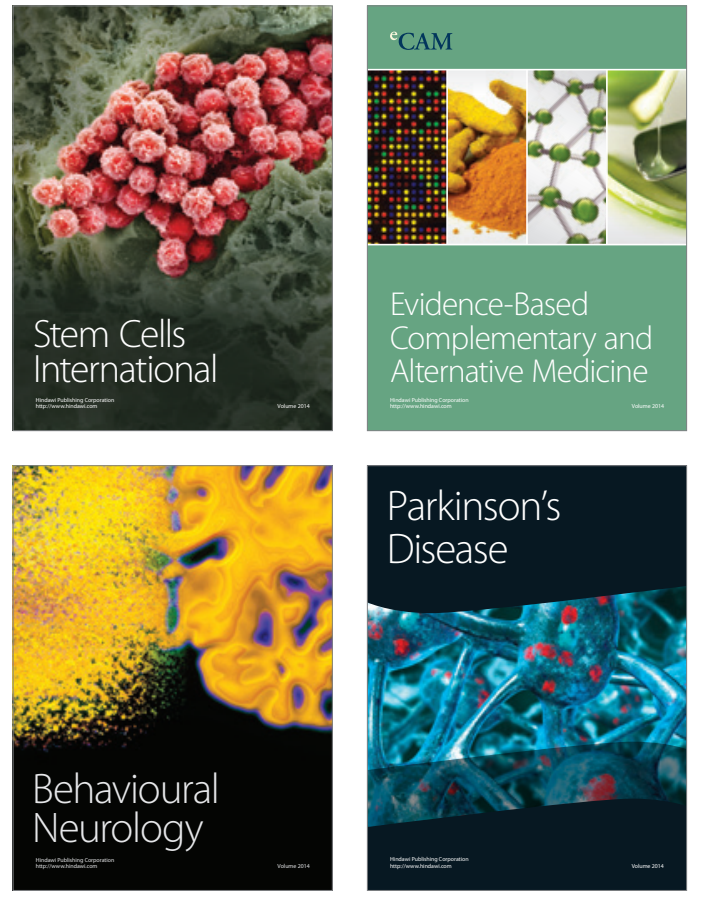
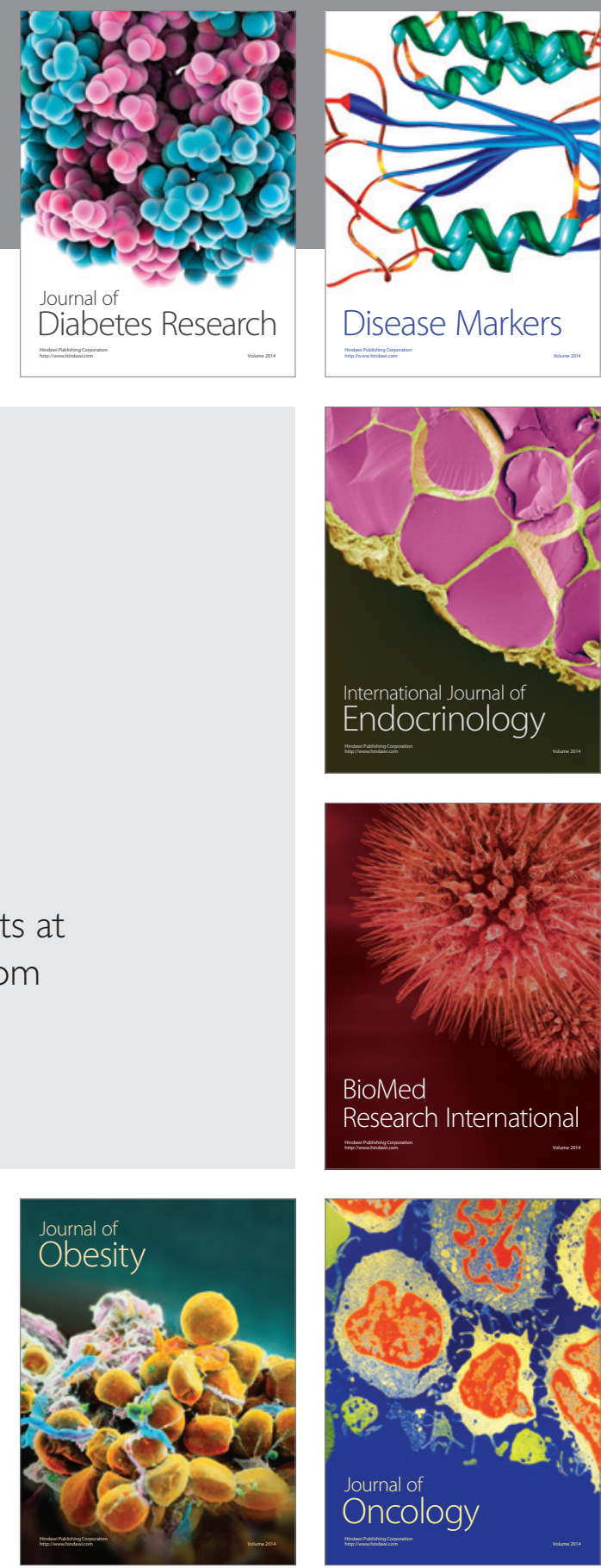

Disease Markers
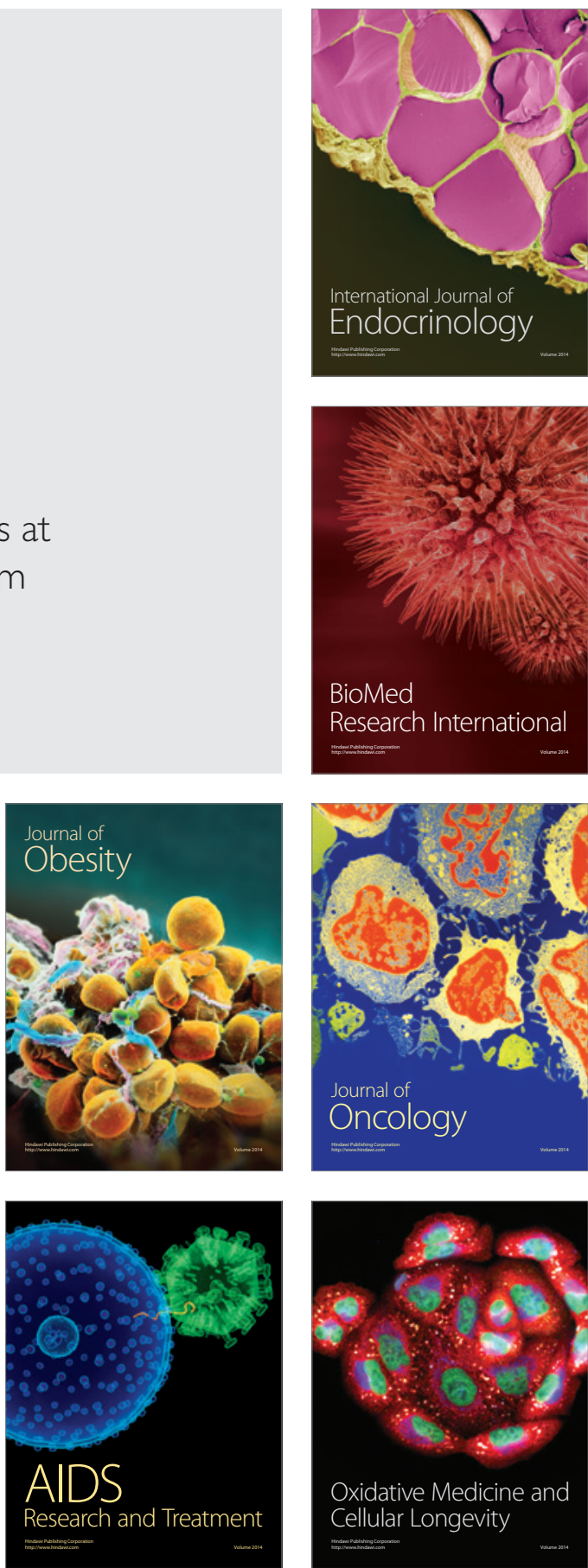